\title{
A CENTER-PERIPHERY MODEL OF MONETARY COORDINATION AND EXCHANGE RATE CRISES
}

Willem H. Buiter

Giancarlo Corsetti

Paolo A. Pesenti

Working Paper No. 5140

\section{NATIONAL BUREAU OF ECONOMIC RESEARCH 1050 Massachusetts Avenue \\ Cambridge, MA 02138 \\ June 1995}

This paper is the preliminary version of a chapter in the Sanwa Foundation Monograph "International Monetary Cooperation and Financial Market Regulation: The Lessons from the 92-93 crisis". We thank Ben Bernanke, Peter Kenen, Guido Rey, Ken Rogoff and the participants in the international and macro seminars at New York University, Yale University and The World Bank for comments and suggestions. This paper is part of NBER's research programs in International Finance and Macroeconomics, and Monetary Economics. Any opinions expressed are those of the authors and not those of the National Bureau of Economic Research.

(c) 1995 by Willem H. Buiter, Giancarlo Corsetti and Paolo A. Pesenti. All rights reserved. Short sections of text, not to exceed two paragraphs, may be quoted without explicit permission provided that full credit, including $\odot$ notice, is given to the source. 


\title{
A CENTER-PERIPHERY MODEL OF MONETARY COORDINATION AND EXCHANGE RATE CRISES
}

\begin{abstract}
The paper analyzes the modalities and consequences of a breakdown of cooperation between the monetary authorities of inflation-prone Periphery Countries that use an exchange rate peg as an anti-inflationary device, when the Center is hit by an aggregate demand shock. Cooperation in the Periphery is constrained to be symmetric: costs and benefits must be equal for all. Our model suggests that there are at least two ways in which a generalized crisis of the exchange rate system may emerge.

The first is when the constrained cooperative response of the Periphery is a moderate common devaluation while the non-cooperative equilibrium has large devaluations by a few countries. An exchange rate crisis emerges if Periphery countries give in to their individual incentives to renege on the cooperative agreement. In the second case, the Center shock is not large enough to trigger a general devaluation in the constrained cooperative equilibrium; yet some of the Periphery countries would devalue in the Nash equilibrium, making the monetary stance in the system more expansionary. In this case, reversion to Nash is collectively rational. We offer this model as a useful parable for interpreting the collapse of the EMR in 1992-93.
\end{abstract}

Willem H. Buiter

Faculty of Economics and Politics

University of Cambridge

Austin Robins Building

Sidgwick Avenue

Cambridge CB3 9DD

UNITED KINGDOM

and NBER

Paolo A. Pesenti

Woodrow Wilson School

Princeton University

Princeton, NJ 08544-1013
Giancarlo Corsetti

Department of Economics

University of Rome III

Via Ostiense 139

00161 Roma

ITALY 


\section{Contents}

1 Introduction 3

2 Exchange rate crises and speculative attacks 5

3 A Center-Periphery model 8

3.1 The Center country . . . . . . . . . . . . . . . . . . . 99 9

3.2 The Periphery countries . . . . . . . . . . . . . . . 10

3.3 Preferences of the policy-makers . . . . . . . . . . . . . 12

3.4 The semi-reduced form . . . . . . . . . . . . . . . . . 14

4 Timing, number and size of realignments in the Periphery 15

4.1 Optimal monetary policy in the Periphery . . . . . . . . . . . . . 16

4.2 Reaction functions in the Center and the Periphery . . . . . . . . 18

4.3 Nash equilibrium . . . . . . . . . . . . . . . . . . . 21

5 Symmetric cooperation in the Periphery $\mathbf{2 4}$

5.1 Policy agreements and national horizontal equity . . . . . . . . . 24

5.2 Optimal monetary policy under symmetric cooperation . . . . . 25

5.3 The cooperative equilibrium . . . . . . . . . . . . . . 26

6 Does cooperation in the Periphery make a difference? 27

6.1 Welfare with positive externalities from monetary expansions in the Periphery. . . . . . . . . . . . . . . . . . . . 28

6.2 Bilateral and effective exchange rates. . . . . . . . . . . 30

7 Policy coordination and exchange rate crises $\quad 34$ 


\section{Introduction}

Post-War history provides evidence that systems of fixed (or quasi-fixed) exchange rates do not survive serious asymmetric disturbances originating in the center country. Undoubtedly, German unification played a crucial role in the currency crises sweeping Europe in 1992 and 1993, in the same way that inflationary pressures in the US at the end of the 1960s were a key determinant of the collapse of Bretton Woods. However, asymmetric disturbances per se need not be disruptive of international monetary arrangements, as they can be counteracted through active cooperation among policy makers. Almost by definition, a crisis of an exchange rate system is a symptom of insufficient or ineffective policy coordination. The contribution of this paper is to provide a model suitable to analyze a currency crisis as primarily a crisis of the policy coordination mechanism underlying the exchange rate arrangement.

Most theoretical analyses treat the demise of a fixed exchange rate regime within the framework of unilateral peg, two-country models. Typically, they focus on the adjustment problem faced by a representative country in the periphery, in the presence of an exogenous shock that undermines the stability of the current exchange rate parity against the center country. In this paper, we argue that the conclusions reached within such framework may be misleading, as the analysis ignores the role played by the coordination (or lack of coordination) of monetary and exchange rate policies among the countries making up the periphery of the system.

Consider the impact on the stability of an exchange rate system of a demand shock in the center country, generating pressures toward a generalized appreciation of its currency. Does cooperation among periphery countries make a difference? This paper will analyze equilibria in which, other things being equal, the number of countries that decide to abandon the fixed exchange rate regime, the jump in the exchange rate following the abandonment of the peg and the average devaluation rate in the system are all endogenous variables that depend on the degree of policy coordination among countries on the periphery of the system. For some realizations of the exogenous shock to macroeconomic fundamentals, the equilibrium allocation under cooperation among the periphery countries is shown to be characterized by a coordinated, symmetric, small realignment by all countries; for the same exogenous shock to macroeconomic fundamentals, there will be other equilibria with uncoordinated, large devaluations by a subset of countries.

In assessing whether and how intra-periphery cooperation enhances the stability (as well as the desirability) of a fixed exchange rate regime, it is crucial to consider which meta 'rules of the game' make policy coordination feasible. In 
our analysis. we build on the idea that cooperation in the periphery is feasible only under a national horizontal equity constraint, according to which no international agreement is enforceable unless countries that are identical ex ante end up having an identical level of welfare ex post. Restricting the set of coordinated strategies by imposing such a requirement is of course controversial. A horizontal equity constraint hampers the possibility of providing insurance against stochastic fluctuations. For example, in the presence of adverse contingencies of the kind analyzed in our paper (asymmetric from the point of view of the center and of the periphery as a whole, yet symmetric with respect, to the periphery countries), the periphery countries could in principle be better-off, ex ante, by adopting rules that, ex post, require only a few of them (possibly randomly selected) to bear the necessary adjustment costs. We believe that the impossibility of making suitable contingent side-payments and the logic of national sovereignty make such schemes time-inconsistent. This paper shows that, imposing a national horizontal equity constraint, the switch from a coordinated to an uncoordinated equilibrium may be collectively rational for some range of the shock to fundamentals.

Multiple rational expectations equilibria or self-fulfilling forces have been advanced as a possible explanation of the collapse of the Exchange Rate Agreement (ERM) during 1992 and 1993. The main alternative set of hypothesis involves the explanation of the collapse in terms of the behavior of fundamentals. In addition to the German unification shock (or syndrome of shocks), among the fundamentals that have been given weight are persistent divergent behavior of national price or unit cost levels, presumably reflecting divergent national monetary and fiscal policies, and the liberalization of international financial capital movements under the Single Act. Our model fits into the category of 'fundamentals explanations', provided the set of fundamentals is augmented to included the rules of the game, that is the behavior of the periphery countries and the center vis-áa-vis each other. While our approach does not rule out the possibility of multiple momentary (instantaneous) equilibria for given fundamentals (including given rules of the game), it goes through even if equilibria are unique. The multiple equilibria explanations, by contrast, rely on multiple momentary equilibria for given fundamentals.

The main focus of this paper is on the role of international policy coordination as a key factor determining the stability of an exchange rate system. Our theoretical framework highlights the possibility that the ERM collapsed (de facto) because of insufficient cooperation among national policy makers, and that this outcome was a collectively rational choice for the members of the periphery.

The paper analyzes the consequences of a switch from cooperative to noncooperative behavior among the periphery countries but does not explain or "endogenize" it. There is evidence, however, that such a switch occurred in the period immediately preceding the crisis. Note that our model does not postulate any change in the strategic relationship between the Center and the Periphery. That relationship is assumed to be non-cooperative (Nash) throughout. Of course, the 
actions chosen by the Center (the value it assigns to its money stock) will, for given fundamentals, be different depending on the nature of the strategic interactions among the members of the Periphery. If fact, our model has the nice implication that there is a range of values for the fundamental for which the Center's monetary policy will be tighter when the Periphery acts non-cooperatively than when it acts cooperatively. The Center's reaction function vis-à-vis the Periphery as a whole is, however, unchanged.

Our theoretical framework highlights the possibility that the ERM collapsed (de facto) because of insufficient cooperation among national policy makers, and that this outcome might have been a collectively rational choice for the members of the Periphery. In the empirical literature on the ERM crisis, it has been extensively documented that asset prices did not seem to anticipate the crisis until very late: a few weeks before the devaluation of the Lira and the Pound in mid September 1992, interest differentials vis-à-vis the D-mark were surprisingly low. What happened at the end of August 1992 that changed the mood of financial markets? There is casual evidence that the frequent public clashes among European policy makers in early September 1992 were correctly interpreted by financial markets as an indicator of a stall in the ERM as a policy coordination mechanism. ${ }^{1}$ The devaluation of a single currency (the lira) on the 13th of September, accompanied by a cosmetic change in the German discount rate, was clearly insufficient to put the ERM on a new stable path: these policy measures were by no means the outcome of a concerted effort to keep the ERM together. Can a change in the perception of the level of cooperation in policy making generate a generalized speculative attack? This paper provides a theoretical framework to address this question.

The paper is organized as follows. After a brief review of the theoretical literature on exchange rate crises in Section 2, we present the model in Section 3. The fourth Section is devoted to the characterization of the Nash equilibrium, followed by a Section on symmetric cooperation. Section 6 explores differences between the two allocations. Section 7 discusses the ERM crisis in the light of our construction.

\section{Exchange rate crises and speculative attacks}

In the literature, there are basically two approaches to modelling exchange rate crises. The first approach, pioneered by Krugman [1979], focuses on the timing and the mechanics of a speculative attack when national authorities pursue adhoc policies that are (bound to be) inconsistent with the indefinite defence of the

\footnotetext{
${ }^{1}$ These clashes are well documented by Kevin Muehring [1992]. Eichengreen and Wyplosz [1993,p. 85] cite the importance of negative (Denmark in the first referendum) or close (France) votes and opinion polls on the Maastricht Treaty as a cause of exchange rate instability in the ERM.
} 
exchange rate parity. In Krugman's model domestic credit expansion persistently exceeds the growth of money demand at a fixed exchange rate. When coupled with an (exogenous) lower bound on international reserves, a 'natural' collapse would finish off the fixed exchange rate regime even if speculative attacks were not feasible. Adding perfect international capital mobility, a weak 'no-arbitrage' condition and interest-sensitive money demand provides a simple framework to describe the dynamics of a collapse brought about by a speculative attack.

The exact timing of an exchange rate crisis, however, may not be determinate if, as suggested by Obstfeld [1986], policies are inconsistent with a peg only conditional on the occurrence of a speculative attack. Consider markets where agents are atomistic (have small net worth, are credit-constrained and do not collude), so that no single speculator can drive international reserves to their minimum threshold level by herself. Then, no one will attack the currency unless she expects that a sufficient number of other agents will do so at the same time (see the discussion in Grilli [1986]). In this case, the timing of a speculative attack becomes indeterminate, as it depends on strategic uncertainty regarding the coordination of the private sector on one particular regime of expectations. In every period during which the fixed exchange rate regime has not yet collapsed, two instantaneous equilibria are possible, one characterized by a run on international reserves leading to an exchange rate crisis and collapse of the parity, another one in which no attack occurs and the peg survives.

The second approach, championed by Flood, Bhandari and Horne [1989], Obstfeld [1991, 1994], De Kock and Grilli [1993], Drazen and Masson [1994], Masson [1995], and Ozkan and Sutherland [1994a,b], looks at optimizing policy makers, who are assumed to have good reasons to peg the currency - for example, a peg is seen as a commitment technology for reducing the undesirable consequences of an inflationary bias, but not at any price. They may, therefore, find it optimal to abandon the exchange rate parity under certain circumstances. According to this approach, an exchange 'crisis' has nothing to do with the availability of reserves and/or the feasibility of defending a peg that is being tested by the international financial markets. Rather, the exchange rate 'crisis' is the implementation of a contingent rule for setting the exchange rate. Each period, the policy maker considers costs and benefits of maintaining the peg for another period and rationally decides whether or not to abandon the parity (to exercise the escape clause). In general, the optimal (contingent) policy rule combines two regimes of monetary policy: in the first one money supply is consistent with the defense of the announced parity, in the second one, monetary policy optimally responds to fundamentals.

As the commitment to defend the announced parity is only imperfectly credible, the expectations game between the private and the public sector may generate multiple instantaneous equilibria. A popular model in the literature assumes imperfect credibility of the peg, perfect capital mobility and one-period wage contracts. With rational expectations, both (one-period) interest, rates and nominal 
wages reflect the probability attached by the private sector to the abandonment of the peg by the policy maker during the next period. When the monetary authorities do not have the ability to precommit credibly vis- $\dot{a}$-vis the private sector, time-consistent policy rules are contingent not only on (exogenous) shocks to velocity, domestic productivity and aggregate demand, but also on the level of wages, that is on endogenous private sector expectations. Typically, there will exist one equilibrium in which private agents coordinate their expectations on low nominal wages and nominal interest rates, while another equilibrium is characterized by high nominal wages and interest rates. The chances that the currently pegged exchange rate parity is not abandoned during the period are high in the first equilibrium, low in the second one. As theory has little to say about the mechanics underlying the coordination of the private sector's expectations, a speculative wave undermining the viability of the peg can be viewed as a sudden switch from one regime of expectations to the other. That is to say, also in the second approach, the exact timing of an exchange rate crisis is indeterminate.

In Krugman [1979], an exchange rate crisis coincides with a speculative attack on the international reserves of the Central Bank. The discrete jump in reserves that is necessary to rule out arbitrage opportunities in the exchange market is determined by a timely drop in the demand for money in anticipation of a positive rate of currency depreciation after the crisis. Thus, for a speculative attack to occur, money demand must be interest-sensitive. ${ }^{2}$ However, if exchange rate crises are seen as rational responses to "excessive" welfare costs of defending a peg, it is certainly possible that such crises may occur in the absence of a speculative attack on international reserves, i.e. regardless of the interest sensitivity of the demand for money. Reserve losses preceding a crisis are certainly possible (and most likely) also in the framework of Obstfeld [1994], appropriately amended so as to include a monetary dimension. ${ }^{3}$ But reserve losses per se would play no role in determining the exchange rate policy.

In this paper, we take the route advocated by Obstfeld and model rational domestic policy makers that minimize an intertemporal loss function. Money demand is not assumed to be interest-sensitive, nor do we explicitly consider international reserves, either as a constraint or as an objective. As our goal is to stress the role of different levels of policy coordination in determining the viability of a fixed exchange rate, in this version of the paper we also omit the analysis of wage formation, i.e. we do not address the first stage of the expectation

\footnotetext{
${ }^{2}$ An interesting multi-country extension of the Krugman approach in which the probability of the collapse of a Periphery country's fixed parity with the Center depends on how many other Periphery countries have already abandoned their peg, can be found in Gerlach and Smets [1994].

${ }^{3}$ When money demand is interest-sensitive, a sudden switch of expectations from high credibility to low credibility of the peg is indeed associated with a pronounced contraction of the demand for domestic money.
} 
game between the private sector and the public sector. Taking nominal wages as given, we focus on policy decision making by domestic governments. It should be clear, however, that there is nothing in the structure of the model that rules out multiple instantaneous equilibria (for given (cooperative or non-cooperative) rules of the game among the policy makers) in the expectation game between private agents and the policy makers. Au contraire, the set of possible equilibria is (not surprisingly) substantially larger in a multi-country than in a two-country model. As our goal is to place center stage the decisive role of international policy coordination in determining the viability of a fixed exchange rate regime, we opt, in order not to dull this focus, to leave backstage the formal analysis of multiple instantaneous equilibria.

\section{A Center-Periphery model}

The economy consists of $N+1$ countries, the first $N$ of which are fully symmetric and represent the Periphery of the system, while the last is the Center. The Center has three unique characteristics. First, it provides a nominal yardstick for the system as a whole by targeting the level, rather than the rate of growth, of the CPI. Second, there is no discrepancy between the target level of output and potential (full-employment) output, so that no inflationary bias affects the economy in a time-consistent equilibrium. Third, it is assumed that all countries in the Periphery trade real goods and services exclusively with the Center, that is, intra-Periphery trade is negligible. No such restriction is imposed on trade in financial claims. This assumption simplifies the analysis considerably, by permitting the omission of algebra-intensive but inessential considerations related to intra-Periphery competitiveness. To emphasize the points of departure with respect to the existing literature, we choose to cast our analysis within the familiar framework of an international monetary policy game, ${ }^{4}$ adopting its standard conventions. Our theoretical construction hinges on the impact of global shocks originating in the Center on the performance and the policies of the Periphery countries. Therefore, the only source of (exogenous) uncertainty is an aggregate demand shock in the Center country. The emphasis on IS shocks is motivated by the stylized facts preceding the collapse of the ERM, such as the fiscal expansion and the investment boom associated with German unification. Nonetheless, our setup could be easily extended to encompass currency substitution shocks or supply-side productivity disturbances. Finally, our assumption about the ex ante symmetry of the Periphery countries, while unrealistic, will help disentangle the specific role of policy coordination in an exchange rate crisis.

All variables other than interest rates are in natural logarithms, and are expressed in terms of deviations from their levels in a zero-disturbance equilibrium. All Center variables are starred, while the Periphery countries are indexed with a

\footnotetext{
${ }^{4}$ See for instance Canzoneri-Henderson [1991], ch.2.
} 
subscript $i$, for $i=1,2, \ldots, N$. Unless otherwise explicitly stated, throughout the paper Greek letters (both lowercase and uppercase) refer to constant, positive parameters.

\subsection{The Center country}

Output supply in the Center, denoted by $y^{*}$, is a deterministic function of employment, $n^{*}$, subject to decreasing returns to scale:

$$
y_{t}^{*}=(1-\alpha) n_{t}^{*} \quad 0<\alpha<1
$$

Labor is supplied inelastically, and profit maximizing competitive firms equate the marginal product of labor ${ }^{5}$ to the real wage. The money wage in the Center is denoted $w^{*}$ while $p^{*}$ is the Center's GDP deflator:

$$
w_{t}^{*}-p_{t}^{*}=-\alpha n_{t}^{*}
$$

Real aggregate demand in the Center depends on the effective real exchange rate of the Periphery vis- $\dot{a}$-vis the Center $z$ (defined below), the Center's real interest rate $r^{*}$ and an aggregate demand shock $\lambda^{*}$ :

$$
y_{t}^{*}=\lambda_{t}^{*}-\delta z_{t}-\nu r_{t}^{*}
$$

The real interest rate in the Center is its nominal interest rate $i^{*}$ minus the expected proportional rate of change in its consumer price index, $q^{*}$ :

$$
r_{t}^{*} \equiv i_{t}^{*}-E_{t} q_{t+1}^{*}+q_{t}^{*}
$$

where the expectation operator conditional on information available in period $t$ is denoted $E_{t}$.

The Center's consumer price index is defined as follows. Let $s_{i, t}$ be the nominal spot exchange rate of the $i^{\text {th }}$ Periphery country (expressed as $i^{\text {th }}$ country's currency per unit of Center's currency) and let $s_{t}$ be the nominal effective exchange rate of the Periphery vis-à-vis the Center, that is,

$$
s_{t} \equiv \frac{1}{N} \sum_{i=1}^{N} s_{i, t}
$$

Similarly, let $p_{i, t}$ be the GDP deflator of the $i^{\text {th }}$ Periphery country (in local currency) and $p_{t}$ the "effective price level" of the Periphery as a whole, that is,

$$
p_{t} \equiv \frac{1}{N} \sum_{i=1}^{N} p_{i, t}
$$

\footnotetext{
${ }^{5}$ Strictly speaking, this should be equal to $-\alpha n_{t}^{*}+\ln (1-\alpha)$. For notational simplicity, the constant term is dropped in what follows.
} 
The effective real exchange rate of the Periphery vis-à-vis the Center. $z$, is then given by

$$
z_{t} \equiv p_{t}^{*}+s_{t}-p_{t}
$$

Assuming a constant share of imports in consumption. 3 (which applies to each of the Periphery countries as well as to the Center). the Center's CPI is defined as follows

$$
q_{t}^{*} \equiv(1-\beta) p_{t}^{*}+\beta\left(p_{t}-s_{t}\right)=p_{t}^{*}-\beta z_{t} \quad 0<\beta<\frac{1}{2}
$$

We restrict the propensity to import $\beta$ to be less than one half, which is equivalent to assuming home bias in consumption in our model. As will become clear later, this assumption rules out the possibility that real interest differentials and real expected depreciation between Center and Periphery move in opposite directions.

Assuming a constant velocity money demand function, equilibrium in the money market requires

$$
m_{t}^{*}=p_{t}^{*}+y_{t}^{*}=w_{t}^{*}+n_{t}^{*}
$$

where $m^{*}$ denotes the Center's nominal money stock. At the end of period $t-1$, that is before the Center money stock $m_{t}^{*}$ is determined and observed, wage setters choose the money wage prevailing in period $t$. Their objective function is to minimize the forecasted deviation of employment from the full-employment level (here normalized to zero). Therefore, they solve

$$
\min _{w_{t}^{*}} E_{t-1} \frac{1}{2}\left(n_{t}^{*}\right)^{2}
$$

subject to eq.(9). Since $n_{t}^{*}=m_{t}^{*}-w_{t}^{*}$, this implies that nominal wages are equal to the expected money supply, and employment (or output) is function only of monetary innovations:

$$
\begin{aligned}
w_{t}^{*} & =E_{t-1} m_{t}^{*} \\
n_{t}^{*} & =m_{t}^{*}-E_{t-1} m_{t}^{*}
\end{aligned}
$$

\subsection{The Periphery countries}

Periphery countries have the same technology as the Center. Thus, using selfexplanatory notation, the supply-side equations characterizing the Periphery are given below.

$$
\begin{gathered}
y_{i, t}=(1-\alpha) n_{i, t} \\
w_{i, t}-p_{i, t}=-\alpha n_{i, t}
\end{gathered}
$$


Define the real exchange rate of the Periphery country $i v i s-\dot{a}$-vis the Center as

$$
z_{i, t}=s_{i, t}+p_{t}^{*}-p_{i, t}
$$

We assume that Periphery countries import (export) goods and services exclusively from (too) the Center country. This is the reason why only the bilateral real exchange rate of country $i$ relative to the Center, $z_{i}$, enters into the demand equation for country $i^{\prime}$ s output:

$$
y_{i, t}=\lambda+\delta z_{i, t}-\nu r_{i, t}
$$

Differently from demand equation in the Center country (3), the parameter $\lambda$ in equation (15) is constant, that is, we abstract from country-specific and timespecific IS shocks hitting the Periphery countries. The only source of exogenous uncertainty is therefore a perturbation of aggregate demand in the Center, which affects all Periphery countries symmetrically. The other behavioral parameters $\delta, \nu$ and $\beta$ are instead identical in both the Center and the Periphery.

Real interest and exchange rates in the $i^{\text {th }}$ country are

$$
\begin{gathered}
r_{i, t}=i_{i, t}-E_{t} q_{i, t+1}+q_{i, t} \\
q_{i, t}=p_{i, t}+\beta z_{i, t}
\end{gathered}
$$

From equation (7) it follows that the Center's real effective exchange rate $z$ can be written as the arithmetic average of the $N$ bilateral real exchange rates $z_{i}$.

$$
z_{t} \equiv \frac{1}{N} \sum_{i=1}^{N}\left(s_{i, t}-p_{i, t}\right)+p_{t}^{*}=\frac{1}{N} \sum_{i=1}^{N} z_{i, t}
$$

By analogy with the Center, real money balances, money wages and employment in the Periphery are determined as follows

$$
\begin{gathered}
m_{i, t}-p_{i, t}=y_{i, t} \\
w_{i, t}=E_{t-1} m_{i, t} \\
n_{i, t}=m_{i, t}-E_{t-1} m_{i, t}
\end{gathered}
$$

We finally assume that assets denominated in different currencies are perfect substitutes in private agents' portfolios, so that the uncovered interest parity condition holds:

$$
i_{i, t}=i_{t}^{*}+E_{t} s_{i, t+1}-s_{i, t}
$$

Note that, given (22), with perfect capital mobility the uncovered interest parity condition must hold for any pair of currencies in the system. 


\subsection{Preferences of the policy-makers}

The preferences of the policy authority in a representative Periphery country $i$ are given in equations (23) (24) and (25):

$$
\begin{array}{cc}
L_{i, t} \equiv E_{t} \sum_{\tau=0}^{\infty} k_{i}^{\tau} \ell_{i, t+\tau} & 0<k_{i}<1 \\
\ell_{i, t} \equiv \frac{1}{2}\left[\left(n_{i, t}-\bar{n}\right)^{2}+\sigma\left(q_{i, t}-\bar{q}_{i, t}\right)^{2}\right]+c I_{i, t} \quad \bar{n}>0 \\
I_{i, t}=0 \text { if } s_{i, t}=\bar{s}_{i, t} ; \quad I_{i, t}=1 \text { otherwise }
\end{array}
$$

where $\bar{s}_{i, t}$ is the announced exchange rate parity and $c$ denotes the exogenously given welfare cost of abandoning the peg. Policy-makers minimize the mathematical expectation of a time-additive loss function defined over the infinite future. The authorities' discount factor is denoted $k_{i}$. The single period loss function $\ell_{i}$ is quadratic in the deviation of actual employment and CPI from their target levels, $\bar{n}$ and $\bar{q}_{i, t}$ respectively. Note that the target level of employment (which is the same everywhere in the Periphery) exceeds the rational-expectations equilibrium or "natural" level, which in this model is equal to zero. Following the standard conventions it is assumed that, because of exogenous (and unremovable) distortions in the Periphery labor market, the full-employment output level is socially suboptimal. The well known theoretical implication of such a conflict between public preferences and equilibrium constraints is that an equilibrium with full monetary discretion does not support the first-best allocation, and the economy of the Periphery is affected by an inflationary bias (à-la-Kydland-Prescott and Barro-Gordon) ${ }^{6}$

According to eq.(24) and (25), realignments in the Periphery (that is, deviations of the realized exchange rate $s_{i, t}$ from its targeted level $\bar{s}_{i, t}$ ) imply an exogenous lump-sum welfare cost equal to $c .^{7}$ These costs are best understood as a proxy for the wide array of non-quantifiable political interests underlying the defense of a given exchange rate target, ranging from nationalistic chauvinism tout-court to fears of professional loss of prestige, reputation and influence; they may also reflect a widespread belief that exchange rate stability is a public good in its own right, even when disentangled from its (possible) anti-inflationary implications. The precise (political-economy) foundations of these devaluation costs

\footnotetext{
${ }^{6}$ Persson and Tabellini [1995] provide un updated survey of the Barro-Gordon-related literature in an open-economy setting.

${ }^{7}$ Our model does not consider the endogenous building up and loss of reputation and credibility of monetary policy. For analytical simplicity, we restrict ourselves to memoryless strategies for the authorities and for the public (when the latter form expectations about future policy). In a less restricted Barro-Gordon-type framework, the penalty for abandoning the fixed parity would be endogenously determined by the equilibrium punishment strategy of the public in a repeated game with the authorities. There would be no need to impose an exogenous cost $c$. Such a modelling strategy is not pursued in this paper for reasons of analytical tractability.
} 
are, however, irrelevant for our purposes. Simply, market participants take the existence of a commitment technology as a datum: the higher the degree of commitment by the policy authority to the defense of the peg (no matter why), the higher the lump-sum costs $c$ the policy authority will "pay" if it reneges its announced target. An extremely high value of $c$ implies that, regardless of internal and external circumstances, the policy authority will subordinate its other objectives to the defense of the current exchange rate. A negligible value signals that governments will always let the currency float or, equivalently, set it at the value most conducive to the achievement of its other objectives. Intermediate values can be rationalized in terms of escape clauses allowing for the possibility of realignments in the presence of specific contingencies, i.e. depending on the size of the shock hitting the domestic economy. ${ }^{8}$

Over time, the CPI target level $\bar{q}_{i, t}$ and the nominal exchange rate target $\bar{s}_{i, t}$ may evolve, but not, independently from each other. It should be kept in mind that, for a given value of the foreign GDP deflator, fixing $\bar{q}_{i, t}$ and $\bar{s}_{i, t}$ is equivalent to targeting some level of the real exchange rate. In this paper, we are not interested in analyzing the implications of the choice of an "incorrect", "misaligned" exchange rate target, relevant as they might be in the analysis of the ERM crisis. In much of what follows we shall rather focus on the case where there is no inescapable conflict between the objectives for the internal and the external value of the currency. The price level target is therefore assumed to evolve consistently with the exchange rate target, as specified in equations (26) and (27):

$$
\begin{aligned}
& \bar{q}_{i, t}=\bar{s}_{i, t} \\
& \bar{s}_{i, t}=s_{i, t-1}
\end{aligned}
$$

Periphery countries target the exchange rate inherited from the previous period, independent of whether a realignment has occurred or not. Once the nominal exchange rate target is set, the CPI target is chosen as well. Both targets are part of the private sector's information set at the time when wage contracts are stipulated. This set of assumptions guarantees that, in an intertemporal model, the effects of a devaluation only last for one period.

Consider now the objective function for the Center country authority as given in equations (28), (29), (30) and (31).

$$
\begin{gathered}
L_{t}^{*} \equiv E_{t} \sum_{\tau=0}^{\infty} k^{* \tau} \ell_{t+\tau}^{*} \quad 0<k^{*}<1 \\
\ell_{t}^{*} \equiv \frac{1}{2}\left[\left(n_{t}^{*}-\bar{n}^{*}\right)^{2}+\sigma\left(q_{t}^{*}-\bar{q}_{t}^{*}\right)^{2}\right]
\end{gathered}
$$

\footnotetext{
${ }^{8}$ In a series of articles, Maurice Obstfeld ([1991] and [1994]) points out that, since escape clauses raise the possibility of multiple equilibria in the disinflation game between the private and public sector, their existence may have destabilizing effects for the fixed exchange rate regime.
} 


$$
\begin{aligned}
& \bar{n}^{*}=0 \\
& \bar{q}_{t}^{*}=0
\end{aligned}
$$

Note that, as regards the objective function, the Center differs from the Periphery in three ways. First, as shown in equation (30), its target level of employment $\bar{n}^{*}$ equals the natural rate of employment (zero), so there is no inflationary bias. Second, as shown in equation (31), the price level target $\bar{q}_{t}^{*}$ is constant. Exchange rate changes therefore do not lead to a "rebasing" of the price level target: there is no price level target drift. Third, the Center does not have an exchange rate target (or welfare losses associated with failing to meet an exchange rate target).

\subsection{The semi-reduced form}

In this Section, we express all endogenous variables as functions exclusively of exogenous, predetermined or control variables. First, consider the bilateral real interest rate differential between the $i^{\text {th }}$ country and the Center country

$$
r_{i, t}=r_{t}^{*}-\beta\left(E_{t} z_{t+1}-z_{t}\right)+(1-\beta)\left(E_{t} z_{i, t+1}-z_{i, t}\right)
$$

By taking the sum over the $N$ periphery countries, the average interest rate differential between the Periphery and the Center will be

$$
\frac{\sum_{i} r_{i, t}}{N}=r_{t}^{*}+(1-2 \beta)\left(E_{t} z_{t+1}-z_{t}\right)
$$

Note that the real interest rate differential and the expected rate of depreciation of the real exchange rate between Center and Periphery move in the same direction if and only if $\beta<1 / 2$, that is, if there is a home bias in consumption.

A few intermediate steps are helpful to characterize the reduced form equation for the Center's effective real exchange rate. First, using the previous expression together with resource constraint of the economy as a whole,

$$
\frac{\sum_{i} y_{i, t}}{N}-y_{t}^{*}=(1-\alpha)\left(\frac{\sum_{i} n_{i, t}}{N}-n_{t}^{*}\right)
$$

we obtain a first order stochastic difference equation in $z_{t}$ :

$$
z_{t}=\gamma E_{t} z_{t+1}+\phi\left(\frac{\sum_{i} n_{i, t}}{N}-n_{t}^{*}\right)-\frac{\gamma}{\nu(1-2 \beta)}\left(\lambda-\lambda_{t}^{*}\right)
$$

where

$$
\gamma \equiv \frac{v(1-2 \beta)}{2 \delta+v(1-2 \beta)} \quad \phi \equiv \frac{1-\alpha}{2 \delta+v(1-2 \beta)}
$$

As the effective real exchange rate $z_{t}$ is a forward looking variable, we impose a no-bubble terminal condition as a boundary condition. Solving equation (35) with such a boundary condition yields

$$
z_{t}=\phi\left(\frac{\sum_{i} n_{i, t}}{N}-n_{t}^{*}\right)+\epsilon_{t}
$$


where $\epsilon_{t}$ is defined as

$$
\epsilon_{t} \equiv \frac{\gamma}{v(1-2 \beta)} \sum_{\tau=0}^{\infty} \gamma^{\top} E_{t}\left(\lambda_{t+\tau}^{*}-\lambda\right)
$$

The effective real exchange rate depends both on the difference between the current monetary innovations in the Periphery and in the Center (which equals the difference between the employment levels in the periphery and the Center) and, through the forward looking variable $\epsilon_{t}$, on current and expected future real demand shocks in the Center relative to the Periphery. Thus, a demand (IS) shock in the Center larger than in the Periphery causes the Center's real exchange rate to appreciate, while a money supply shock in the Center larger than in the Periphery causes the Center's real exchange rate to depreciate. The stochastic variable $\epsilon_{t}$ is the exogenous shock to the fundamentals of our international economy. It bears emphasizing that the current realization of $\epsilon_{t}$ is the 'present discounted value' of current and expected future demand disturbances over the infinite horizon. ${ }^{9}$

Next, it is straightforward (albeit algebraically tedious) to show that the bilateral real exchange rate of Periphery Country $i$ vis-à-vis the Center is

$$
z_{i, t}=\xi(1-\theta) n_{i, t}-\xi \theta \sum_{j \neq i} n_{j, t}-\phi n_{t}^{*}+\epsilon_{t}
$$

where

$$
\theta \equiv\left(\frac{\delta-\nu \beta}{2 \delta+\nu(1-2 \beta)}\right) \frac{1}{N}, \quad \xi \equiv \frac{1-\alpha}{\delta+\nu(1-\beta)}=\frac{\phi}{1-N \theta}
$$

Finally, we write the semi-reduced form equations for the CPI level

$$
q_{i, t}=[\alpha+\beta \xi(1-\theta)] n_{i t}-\beta \xi \theta \sum_{j \neq i} n_{j, t}-\beta \phi n_{t}^{*}+w_{i t}+\beta \epsilon_{t}
$$

and the bilateral nominal exchange rate vis- $\dot{a}$-vis the Center

$$
s_{i, t}=[\alpha+\xi(1-\theta)] n_{i, t}-\xi \theta \sum_{j \neq i} n_{j, t}-(\alpha+\phi) n_{t}^{*}+w_{i t}-w_{t}^{*}+\epsilon_{t}
$$

\section{Timing, number and size of realignments in the Periphery}

We now construct and characterize the Nash equilibrium of the monetary policy game between the Center and the $N$ countries in the Periphery of the system,

\footnotetext{
${ }^{9}$ It is also important to observe that, while all results in this paper are expressed in state space, that is as functions of the size of the shock $\epsilon_{t}$, it is straightforward to reinterpret them in terms of time series once the dynamic process followed by $\lambda_{t}^{*}$ is specified. For instance, our analysis of the "timing" of a realignment in the next sections, formulated in state space, could equivalently be cast in dynamic terms without major modifications to the strategy of solution.
} 
for given wages ${ }^{10}$. In the next Section we will look at a cooperative (symmetric) game. While the objective functionals of both Periphery and Center are defined over an infinite horizon, the Nash and cooperative solutions are the same as those that would be obtained if, each period, the authorities were to act myopically by minimizing the single-period objective function $\ell_{i, t}$ or $\ell_{t}^{*}$ only. The features of the model that make for this considerable simplification are the following. First, there is no intertemporal carry-over, either through wage setting ${ }^{11}$ or through asset accumulation. Second, the time-consistent solutions we are considering are restricted to memoryless strategies: current and anticipated future policy actions are not affected by the past history of the game (that, is, the actual sequences of policy actions). Third, while our model has two structural lags and forward-looking expectations (through the real interest, rates and the uncovered interest parity relationships), its no-bubble solution(s) do not involve any state variables. The only "dynamics" in the model come from the assumption that the money wage is set one period in advance, from the behavior of the target nominal exchange rate of the periphery countries and through the forward-looking expectational variables. Neither the lag in money wage setting, nor the lag in the determination of the target nominal exchange rate result in a proper, predetermined, state variable entering the reduced form of the model.

While in our model the policy instruments are the stocks of domestic money, it is notationally convenient to express our results in terms of monetary innovations $\left(m_{i, t}-E_{t-1} m_{i, t}\right.$ and $\left.m_{t}^{*}-E_{t-1} m_{t}^{*}\right)$ which, in our setup, translate one-to-one into employment $\left(n_{i, t}\right.$ and $\left.n_{t}^{*}\right)$. ${ }^{12}$

\subsection{Optimal monetary policy in the Periphery}

The optimal policy rule for a representative periphery countries combines two different monetary regimes. In one the money stock takes on the value consistent with the survival of the peg. In the other one the peg is abandoned and the money supply optimally responds to fundamentals. Consider the optimal monetary policy conditional on the peg being abandoned. Once the current exchange rate parity is no longer a (binding) target or constraint, the policy maker will

\footnotetext{
${ }^{10} \mathrm{It}$ is worth emphasizing that the Center is not a Stackelberg leader. Throughout this section, the Center and each individual member of the Periphery play Nash vis-à-vis all other players.

${ }^{11}$ In these sections we treat money wages in the Periphery and the Center as given. Since wages are set one period ahead, this is clearly the right assumption to make if time-consistent. solutions are considered.

${ }^{12}$ Note, from equation (eq.(42)), given the realization of the aggregate demand shock $\lambda_{i}^{*}$ in the Center (that is, given $\epsilon_{t}$ ), and taking as given wages and monetary policies in the rest of the system, there is also a one-to-one relation between employment in a Periphery country and its nominal exchange rate.
} 
minimize the loss function $\ell_{i, t}$ by choosing $m_{i, t}$ such that :

$$
\frac{\partial \ell_{i, t}}{\partial m_{i, t}}=n_{i, t}^{F L}-\bar{n}+\sigma[\alpha+\beta \xi(1-\theta)]\left(q_{i, t}^{F L}-\bar{q}\right)=0
$$

where the superscript "FL" refer to "conditional on abandoning the peg". Solving the above expression for the $i^{\text {th }}$ country's monetary policy yields

$$
n_{i, t}^{F L}=\frac{\left[\bar{n}-\Lambda\left(w_{i t}+\beta \epsilon_{t}-\beta \xi \theta \sum_{j \neq i} n_{j t}-\beta \phi n_{t}^{*}-\bar{q}_{i t}\right)\right]}{A[\alpha+\xi(1-\theta)]}
$$

where

$$
A \equiv \frac{1+\sigma[\alpha+\beta \xi(1-\theta)]^{2}}{\alpha+\xi(1-\theta)}, \quad \Lambda \equiv \sigma[\alpha+\beta \xi(1-\theta)]
$$

The policy maker will opt for abandoning the peg if and only if the loss under a peg is larger than the loss associated with a devaluation, including the lump-sum welfare cost $c$ :

$$
\frac{1}{2}\left\{\left[\left(n_{i, t}^{F X}-\bar{n}\right)^{2}+\sigma\left(q_{i, t}^{F X}-\bar{q}_{i, t}\right)^{2}\right]-\left[\left(n_{i, t}^{F L}-\bar{n}\right)^{2}+\sigma\left(q_{i, t}^{F L}-\bar{q}_{i, t}\right)^{2}\right]\right\} \geq c
$$

where "FX" refers to "conditional on defending the peg". A simple yet insightful way to characterize the optimal switching rule between the two regimes can be characterized as follows.

Define the shadow devaluation rate (henceforth the SDR) as the difference between the (optimally chosen) value of the exchange rate if the peg were abandoned and the target exchange rate. The SDR will be denoted $\Delta \tilde{s}_{i, t}$. By definition, the exchange rate prevailing conditional on the abandonment of the peg will be $s_{i, t}=\bar{s}_{i, t}+\Delta \tilde{s}_{i, t}$.

An expression for the SDR can be obtained by using $n^{F L}$ in (44) together with the reduced form for the nominal exchange rate (42):

$$
\begin{gathered}
\Delta \tilde{s}_{i t}=\frac{1}{A}\left[\bar{n}+(A-\beta \Lambda) \epsilon_{t}+A\left(w_{i, t}-\bar{s}_{i, t}-w_{t}^{*}\right)-(A-\beta \Lambda) \xi \theta \sum_{j \neq i} n_{j, t}\right]- \\
-\frac{1}{A}\left\{[A(\alpha+\phi)-\beta \phi \Lambda] n_{t}^{*}-\Lambda\left(\bar{q}_{i, t}-w_{i, t}\right)\right\}
\end{gathered}
$$

This expression can be simplified considerably by rewriting the SDR as a function of either the employment gap $n_{i, t}^{F X}-n_{i, t}^{F L}$ or the price level gap $q_{i, t}^{F X}-q_{i, t}^{F L}$ in the two alternative exchange rate regimes:

$$
\Delta \tilde{s}_{i, t}=[\alpha+\xi(1-\theta)]\left(n_{i, t}^{F L}-n_{i, t}^{F X}\right)=\left[\frac{\alpha+\xi(1-\theta)}{\alpha+\beta \xi(1-\theta)}\right]\left(q_{i, t}^{F L}-q_{i, t}^{F X}\right)
$$

Since the optimal choice of exchange rate regime (46) only involves the evaluation of the employment gap and the price level gap, it follows, substituting equation 
(48) into eq.(46), that the authorities will abandon the peg if and only if condition (49) holds:

$$
\left|\Delta \tilde{s}_{i, t}\right| \geq \sqrt{\frac{2 c[\alpha+\xi(1-\theta)]}{A}} \equiv \tilde{c}
$$

In other words, there exists a threshold value of the shadow depreciation rate that trigger an optimal devaluation (or revaluation). The threshold value $\tilde{c}$, defined by the right, hand side of the above inequality, translates the welfare cost of abandoning the peg into the metric of the SDR. Note that $\tilde{c}$ is constant and defined symmetrically for both positive and negative rates of devaluation. By using (49), the exchange rate behavior of the $i^{\text {th }}$ Periphery country implied by its optimal monetary policy can now be completely characterized as follows

$$
\begin{array}{ll}
s_{i, t}=s_{i, t}^{F X} \equiv \bar{s}_{i, t} & \text { if }\left|\Delta \tilde{s}_{i, t}\right| \leq \tilde{c} \\
s_{i, t}=s_{i, t}^{F L} \equiv \bar{s}_{i, t}+\Delta \tilde{s}_{i, t} & \text { if }\left|\Delta \tilde{s}_{i, t}\right| \geq \tilde{c}
\end{array}
$$

How does this result relate to the existing literature on currency crises and speculative attacks? In the context of the first-generation speculative attack models, Flood and Garber [1984] showed that the private sector will launch a speculative attack depleting reserves and forcing an abandonment of the fixed parity as soon as the path of the shadow floating exchange rate crosses the fixed parity from below. In our setup, the government will choose to abandon the fixed parity as soon as the shadow floating exchange rate exceeds the fixed rate by a margin sufficient to cover the fixed cost of abandoning the peg. There are therefore two differences. First, in our approach the public sector, arbitrating utility across exchange regimes, decides whether or not to abandon the parity. Second, the fixed cost of abandonment means that the shadow floating exchange rate can differ from the parity by some margin without triggering any realignment.

\subsection{Reaction functions in the Center and the Periphery}

Consider first the reaction function in the Center country. Since the Center always plays Nash, regardless of whether Periphery countries coordinate their actions, its optimal monetary policy is given by

$$
n_{t}^{*}=H\left[\beta \phi \frac{1}{N} \sum_{i} n_{i, t}+\beta \epsilon_{t}-w_{t}^{*}\right]
$$

where

$$
H \equiv \frac{\sigma(\alpha+\beta \phi)}{1+\sigma(\alpha+\beta \phi)^{2}}
$$

Equation (51) reveals that, ceteris paribus, the Center will always find it optimal to react to a monetary expansion in the Periphery by increasing its own money 
supply. From the point of view of the Center, its monetary policy action and the monetary policy actions of each of the Periphery countries are strategic complements ${ }^{13}$. The intuition is straightforward. Given its preferences (eq. (29)), the Center always equates, at the margin, the costs of price level instability to the benefits from bringing employment closer to the natural rate level. To the extent that a monetary expansion in the Periphery brings about a depreciation of the Periphery's effective real exchange rate $z,{ }^{14}$ the CPI in the Center will fall together with the price of imported goods. The Center's employment is of course only affected by its own monetary policy. Therefore, as a result of the monetary expansion in the Periphery, the benefit, at the margin, from more expansionary monetary policy (to stabilize the Center's CPI) exceeds the cost of slightly increasing employment beyond the target level. Consequently, the Center's monetary authority will be willing to implement more expansionary monetary policies.

Due to the presence of lump-sum realignment costs, the reaction function for the representative Periphery country is discontinuous: if $\left|\Delta \tilde{s}_{i, t}\right| \leq \tilde{c}$,

$$
n_{i, t}=\frac{1}{[\alpha+\xi(1-\theta)]}\left[\bar{s}_{i, t}-w_{i t}+w_{t}^{*}+\xi \theta \sum_{j \neq i} n_{j, t}+(\alpha+\phi) n_{t}^{*}-\epsilon_{t}\right]
$$

while if $\left|\Delta \tilde{s}_{i, t}\right| \geq \tilde{c}$,

$$
\begin{aligned}
n_{i, t} & =\frac{1}{[\alpha+\xi(1-\theta)]}\left[\bar{s}_{i, t}+\Delta \tilde{s}_{i, t}-w_{i t}+w_{t}^{*}+\xi \theta \sum_{j \neq i} n_{j, t}+(\alpha+\phi) n_{t}^{*}-\epsilon_{t}\right]= \\
& =\frac{1}{A[\alpha+\xi(1-\theta)]}\left[\bar{n}-\Lambda\left(w_{i t}-\bar{q}_{i t}+\beta \epsilon_{t}-\beta \xi \theta \sum_{j \neq i} n_{j t}-\beta \phi n_{t}^{*}\right)\right]
\end{aligned}
$$

\footnotetext{
${ }^{13}$ Player $j$ 's action, $n_{j}$, is a strategic complement with respect to player $i$ 's action $n_{i}(i \neq j)$ if the magnitude of the optimal action of player $i$ increases whenever player $j$ increases the magnitude of her action, that is, if and only if $\partial n_{i} / \partial n_{j}>0$ (see Bulow, Geanakoplos and Klemperer [1985]). In the two-player case the reaction curve of player $i$ would be upwardsloping. When $\theta$ is negative, then $\partial n_{i} / \partial n_{j}<0$, country $j$ 's action is instead a strategic substitute with respect to country $i$ 's action.

${ }^{14} \mathrm{~A}$ real depreciation of $z$ is a straighforward result when all Periphery cotntries simultaneously expand, because every currency depreciates vis-à-vis the Center (eq.(37)). Less obvious is the case in which only a few countries in the Periphery increase their money supply. A monetary expansion in country $i$ brings about, ceteris paribus, a depreciation of its bilateral real exchange rate $z_{i, t}(39)$. The elasticity of the bilateral real exchange rate with respect to the money supply is, in fact, equal to $\xi(1-\theta)$, which is unambiguously positive for $\beta<1 / 2$. However, an expansion in one country will have repercussions on all other Periphery conntries, even if they do not change their monetary stance. More precisely, an expansion in country $i$ tends to appreciate country $j^{\prime} s$ real exchange rate against the Center if $\theta>0$, and to depreciate it if $\theta<0$. Can these indirect effects of a monetary expansion in country $i$ prevail over its direct effect? The answer to this question is, by equation (37), negative, independently of the sign of $\theta$. The Periphery real effective rate $z$ unambiguously depreciates as a consequence of a monetary expansion by any subset of countries in the Periphery.
} 
The expressions for the $N$ reaction functions of each of the periphery countries system make it clear that for each Periphery country, its money stock and the Center's money stock are strategic complements. Among the Periphery countries, the money stocks of any pair of countries, $j$ and $i$, say, are strategic complements if and only if $\theta$ is positive: the best response to country $j^{\prime} s$ monetary expansion unambiguously implies an increase of domestic money supply in country $i$. If $\theta<0$, Periphery countries' policy instruments are strategic substitutes.

The sign and the magnitude of the coefficient $\theta$ is central to our interpretation of the reaction functions and the Nash equilibrium they support, becalıse $\theta$ is a synthetic indicator of policy spillovers in the system. As Intra-Periphery externalities play a crucial role in the solution of our model, it is important to analyze their nature and implications in detail.

Consider the equilibrium condition in the goods market of the Center (eq. (3)). Other things equal, a real depreciation of the Periphery country $i^{\prime} s$ currency shifts demand in the Center away from the goods produced either in the Center or in the rest of the Periphery and toward country $i^{\prime} s$ goods ${ }^{15}$. This is the expenditureswitching effect associated with a monetary expansion in country $i$, that lowers aggregate demand in the rest of the Periphery. However, as supply in the Center is unchanged, equilibrium requires a fall in the Center's real interest rate. Ceteris paribus, the fall of $r^{*}$ lowers the real interest rate in the other countries and boosts demand for the Periphery's output. This is the expenditure-changing impact of a monetary expansion in country $i$ : it increases global demand by lowering the "world" interest rate.

What matters here is the sign and the magnitude of the elasticity of the real interest rate $r_{j, t}$ in country $j$ with respect to country $i^{\prime} s$ real exchange rate, $z_{i, t}$, implicitly given by eq. (32). This elasticity is equal to $\beta-(\delta / \nu)$, and, by (40), proportional to the negative of $\theta$. Remember that all goods market interaction among the periphery passes through the Center. A positive value of $\theta$, corresponding to a large value of $\delta$, means that monetary expansion in Periphery country $i$ (which causes a depreciation of $i^{\prime} s$ bilateral real exchange rate with the Center) will determine a large fall in demand for Center output. For a given domestic supply in the Center, the real interest rate will have to fall a lot to re-equilibrate the market for Center output. This decline in the real interest rate is transmitted to the other periphery countries. They now face excess demand at their old bilateral real exchange rate with the Center and will experience a real appreciation.

If $\theta>0$, the expenditure-changing effect prevails over the expenditure-switching effect of a monetary expansion by one Periphery country: the real exchange rate

\footnotetext{
${ }^{15}$ Given the constant velocity money demand function $m_{i, t}=p_{i, t}+y_{i, t}$ and the output supply function $y_{i, t}=\alpha\left(m_{i, t}-w_{i, t}\right)$, it follows that with $\alpha<1$ (and predetermined wages) country $i^{\prime} s$ GDP deflator increases with its nominal money stock, but less than proportionally and its real output expands. The increase in aggregate demand (eq.15) that matches the increase in supply requires a real depreciation and a fall of the real interest rate.
} 
appreciates and the real interest rate falls in the rest of the Periphery. With a positive $\theta$, expansionary policies in the periphery are therefore "beggar thy neighbor" in terms of the international competitiveness of the other Periphery countries. On the other hand, if $\theta<0$, the spillovers associated with a monetary expansion by one country have the opposite sign: the real interest rate must increase in all Periphery countries that do not expand, while their bilateral real exchange rates depreciate against the Center. This is the case of a prevailing expenditure-switching effect. ${ }^{16}$

As an important implication of a dominant expenditure-changing effect, a monetary expansion in one country tends to enhance the stability of the peg in all other Periphery countries, because it lowers the shadow depreciation rate for any level of the shock. In fact, from (47), we have

$$
\frac{\partial \Delta \tilde{s}_{i, t}}{\partial n_{j, t}}=-(A-\beta \Lambda) \xi \theta<0 \quad \text { if } \theta>0
$$

Vice versa, if $\theta<0$, the SDR in one country increases with a monetary innovation in any other country.

\subsection{Nash equilibrium}

We focus on the following Nash equilibrium. The support of the shock $\epsilon_{t}$ is split into five segments, defined in terms of four thresholds (denoted $\epsilon^{d}, \bar{\epsilon}^{d}, \epsilon^{a}$ and $\bar{\epsilon}^{a}$, and such that $\epsilon^{a}<\bar{\epsilon}^{a}<\epsilon^{d}<\bar{\epsilon}^{d}$ ). Although we drop the time subscript. for notational convenience, it is worth noticing that these thresholds need not be constant over time. ${ }^{17}$ With this in mind, we show that, in equilibrium, all Periphery countries defend the peg when the shock $\epsilon_{t}$ falls between $\bar{\epsilon}^{a}$ and $\epsilon^{d}$; all Periphery countries jointly devalue their currencies by the same percentage when the shock is larger than $\bar{\epsilon}^{d}$; all Periphery countries jointly revalue their currencies by the same percentage when the shock is smaller than $\bar{\epsilon}^{a}$; a number $N^{F L}$ of Periphery countries (with $0 \leq N^{F L} \leq N$ ) devalue their currencies while a number $N-N^{F L}$ maintain the peg when the shock falls between $\epsilon^{d}$ and $\bar{\epsilon}^{d}$; a number $N^{F L}$ of Periphery countries revalue their currencies while a number $N-N^{F L}$ maintain the peg when the shock falls between $\epsilon^{a}$ and $\bar{\epsilon}^{a}$. In this equilibrium, no Periphery country finds it optimal to devalue against the Center when some other Periphery country revalues instead.

\footnotetext{
${ }^{16} \mathrm{~A}$ qualitatively similar result is considered by Obstfeld and Rogoff [1995] in their model of international monetary transmission with monopolistic suppliers. The effects of foreign money supply increases on home output are found to be ambiguous, as they depend on the size of the consumption elasticity of money demand (a parameter that, in their model, plays substantially the same role as $\theta$ does in our setup).

${ }^{17} \mathrm{It}$ is of course straightforward to translate all statements concerning the effects of the size of the shock on a particular event into statements on the timing of the event itself.
} 
Our strategy of solution focuses first on equilibrium outcomes involving (possibly) devaluations by some countries. Conjecture the existence of a realization of the shock, say $\epsilon_{t}=\hat{\epsilon}_{t}$, such that each country is indifferent between maintaining the peg and abandoning it (note that, holding constant country $i / s$ money stock, this shock would have an inflationary impact in country i). In other words, at $\hat{\epsilon}_{t}$ it must be the case that the deflationary and recessionary costs associated with the defense of the peg are just equal to the lump-sum realignment costs that are incurred when the parity is abandoned in order to improve external competitiveness and boost aggregate demand. By conditions (50), it is obvious that this is possible if and only if the SDR, evaluated at $\hat{\epsilon}_{t}$, is equal to $\tilde{c}$ for each country in the Periphery:

$$
\Delta \tilde{s}_{i, t}\left[\hat{\epsilon}_{t}\right]=\tilde{c} \quad i=1,2, \ldots, N
$$

Given that the Periphery countries are indifferent between a peg and a float, denote by $N^{F L}$ the number of countries that decide to realign. Since the countries that choose to abandon the peg devalue (optimally) by a percentage $\tilde{c}$, the average actual depreciation rate is

$$
\frac{1}{N} \sum_{i=1}^{N}\left(s_{i t}-\bar{s}_{i t}\right)=\frac{N^{F L}}{N} \Delta \tilde{s}_{i, t}\left[\hat{\epsilon}_{t}\right]=\frac{N^{F L}}{N} \tilde{c}
$$

Substituting this expression into the reaction functions of the Center and the Periphery and solving the system, the percentage of countries that in equilibrium must abandon the peg for our conjecture to be true is given by

$$
\frac{N^{F L}}{N}=\frac{1}{\tilde{c} \Omega_{3}}\left[\bar{n}+\Omega_{1} \hat{\epsilon}_{t}-\Omega_{2} \sum_{i=1}^{N} \frac{\bar{s}_{i, t}-w_{i, t}}{N}-\Omega_{4} w_{t}^{*}-\Lambda \sum_{i=1}^{N} \frac{w_{i, t}-\bar{q}_{i, t}}{N}-A \tilde{c}\right]
$$

where the $\Omega_{k}$ coefficients $(k=1, \ldots, 4)$ are functions of the parameters of the model, as summarized in Table 1.

$$
\begin{array}{|l}
\text { TABLE 1 } \\
\Omega_{1}=(A-\beta \Lambda)\left\{1+[1-\beta H(\alpha+\phi)] \omega_{1}\right\}-\alpha \beta H \omega_{2} \\
\Omega_{2}=\Omega_{1}+\beta \Lambda+\beta H(\alpha+\phi)\left[(A-\beta \Lambda) \omega_{1}+\omega_{2}\right] \\
\Omega_{3}=\Omega_{2}-A \\
\Omega_{4}=\Omega_{2}-H(\alpha+\phi)\left[(A-\beta \Lambda) \omega_{1}+\omega_{2}\right] \\
\text { where } \\
\omega_{1}=\frac{\xi \theta(N-1)}{(\alpha+\phi)(1-H \beta \phi)} \\
\omega_{2}=\frac{A(\alpha+\phi)-\beta \Lambda \phi}{(\alpha+\phi)(1-H \beta \phi)}
\end{array}
$$


The proportion of countries abandoning the peg in equilibrium is a linear function of target exchange rate, the target price level, the predetermined wage rates and the realization of the shock (where it can be shown that the coefficient of the latter variable, $\Omega_{1} / \Omega_{3}$, is positive).

Equation (58) implies that, in accordance with our conjecture, each country is indeed indifferent between abandoning or maintaining the announced exchange rate parity, provided that the required number of countries $N^{F L}$ devalue in the aggregate. Note that, with ex-ante identical countries, the set of countries implementing a devaluation is indeterminate.

Nonetheless, the range of shocks within which our conjecture is valid is limited by the fact that $N^{F L}$ must lie between 0 and the number of countries in the system (i.e. $0 \leq N^{F L} / N \leq 1$ ) - note that, for expositional convenience, we ignore the constraint that $N^{F L}$ be an integer. The range of values for the shock such that all countries will be indifferent between maintaining the parity and devaluing by $\tilde{c}$ can thus be determined by setting $N^{F L}=0$ and $N^{F L}=N$ in equation (58), and solving for the corresponding threshold values, $\epsilon^{d}$ and $\bar{\epsilon}^{d}$. For shocks larger than $\bar{\epsilon}^{d}$, all countries in the periphery will devalue by the same optimal rate $\Delta \tilde{s}_{i, t} \geq \bar{c}$. For shocks smaller than $\bar{\epsilon}^{d}$, the Periphery countries will either maintain the peg or resort to a revaluation.

The case of an equilibrium involving a revaluation by (possibly) some countries but a devaluation by none, is perfectly symmetric. For a shock $\epsilon_{t}=-\hat{\epsilon}_{t}$, the average actual appreciation rate in the periphery is

$$
-\frac{1}{N} \sum_{i=1}^{N}\left(s_{i t}-\bar{s}_{i t}\right)=\frac{N^{F L}}{N} \tilde{c}
$$

while expression (58) still defines the number of countries abandoning the peg in equilibrium. It will thus be possible to define two threshold values for the shock $\left(\epsilon^{a}\right.$ and $\left.\bar{\epsilon}^{a}\right)$ such that each individual country will be indifferent between maintaining the peg and letting the currency appreciate by $\tilde{c}$. All countries will revalue their currency for $\epsilon_{t} \leq \underline{\epsilon}^{a}$, while all countries will maintain the unilateral peg for $\bar{\epsilon}^{a} \leq \epsilon_{t} \leq \underline{\epsilon}^{a}$.

It should be stressed that, in the Nash equilibrium under consideration, $\mathrm{Pe}$ riphery countries that start, off being identical also share the same level of welfare ex post for any realization of the shock, even when their exchange rate policies differ.

The equilibrium outcome is illustrated by Figure 1. The graph at the top plots the fraction of countries abandoning the peg against the support of the shock $\epsilon$; the second graph plots, for each country that abandons the peg, that country's actual depreciation rate. The graph at the bottom presents the information contained in the first two graphs in a different way, by plotting the average depreciation rate of the Periphery as a whole vis-à-vis the Center. 


\section{Symmetric cooperation in the Periphery}

In this Section we look at a behavioral alternative to Nash, involving international policy coordination. The case we focus on has all Periphery countries cooperating to maximize their joint welfare, as measured by (minus) the sum of their domestic loss functions $\left(-\sum_{i=1}^{N} E_{t} L_{i, t}\right)$.

In what follows, the Center's monetary policy always represents the optimal reaction to policies in the Periphery, independently of whether these are coordinated or not. Our maintained hypothesis is that cooperation is perceived in the Center as an unacceptable compromise on internal objectives. ${ }^{18}$ We therefore abstract from issues regarding cooperation between the Center and the Periphery. ${ }^{19}$ Also, throughout the analysis, we assume that side-payments between countries are ruled out.

\subsection{Policy agreements and national horizontal equity}

Even though all Periphery countries are structurally identical, this need not al1tomatically imply that in a cooperative equilibrium they would either achieve equal welfare or adopt the same policies. Obviously, the existence of the fixed (sunk) per-country cost of abandoning the parity implies that, for small shocks $\epsilon_{t}$, it might be efficient (as regards the sum of the national welfare levels) to have but a few countries devalue, even if ex-post this would make the "scapegoat" countries worse off than the remaining countries that stick to their fixed parities.

If an agreement reached before the realization of $\epsilon_{t}$ is observed can be enforced ex-post (possibly through the involvement of some third party), then the participation constraint in a cooperative agreement need only be specified in terms of the expected value of the loss function: the expected welfare under the cooperative agreement must be no less for each Periphery nation than the expected welfare if each Periphery nation were to play Nash. This kind of ex-ante agreement, which

\footnotetext{
${ }^{18}$ To boost this interpretation, some authors have pointed out that, to the extent that the antiinflationary credibility of the conservative central bank in the Center country is undermined, Center-Periphery coordination may not be in the interest of the Periphery either (Alesina and Grilli [1993]).

${ }^{19}$ Ignoring the semantic consideration that the loss of national sovereignty associated with a cooperative agreement is at odds with the hierarchical structure implicit in a Center $" s$. Periphery setup, and leaving aside any considerations regarding the possible empirical realism of such a framework, there is an obvious motivation underlying our modelling strategy: we want to concentrate on those aspects of policy interaction in a multi-country monetary game that, so far, have not been thoroughly examined in the literature, in spite of their evident. theoretical interest and policy implications. The question we want to address is whether policy coordination among those countries symmetrically affected by a shock originating in the "main" country of the system (thus, an asymmetric shock for the system as a whole) makes the system itself more (or less) vulnerable to currency crises and speculative attacks. Our setup focuses on those aspects of a multi-country game which are directly related to our main objective; from this perspective, theoretical generalizations would represent unnecessary detours.
} 
both eliminates strategic uncertainty and provides the Periphery nations with a form of insurance against unfavorable states of the world, permits, in principle, ex-post differences in both national policy actions and national welfare levels. ${ }^{20}$

In what follows we will restrict the analysis to the case of symmetric cooperative agreements, in which the behavior of each single Periphery country is equal to the average behavior of the Periphery as a whole: if a realignment occurs, all Periphery countries realign simultaneously and by the same amount. Of course, even in the absence of a constraint imposing that all Periphery nations should devalue jointly, for any size of the externality (measured by $\theta$ ) it is always possible to determine a value of the shock large enough to ensure that all Periphery nations will devalue symmetrically even in an unconstrained cooperative agreement. ${ }^{21}$ We believe, however, that there is more to be said in defense of our assumption of symmetric cooperative behavior than that under certain conditions it may be consistent with unrestricted cooperative behavior. We wish to impose as a "primitive" a national horizontal equity constraint in the joint maximization problem defining the cooperative agreement. This constraint states that no Periphery nation can enter into any agreement that would, ex-post, make it, worse off than any other Periphery nation. In other words, no discrepancy in welfare levels among the Periphery countries is permitted under any circumstances. This restriction of identical ex-post utility levels translates, when all intra-Periphery externalities are taken into account and side-payments are ruled out, into a restriction of symmetric use of the policy instruments.

Summarizing, we rule out the possibility of "asymmetric" cooperative behavior in the Periphery: the only alternative to symmetric cooperative behavior is undiluted Nash. Under Nash, of course, the ex-post utility levels of all Periphery countries are always the same, regardless of whether they realign or not. The justification for our assumption of national horizontal equity lies in the realm of political economy. Slightly milder forms of this restriction at work can be found in the newspapers every day.

\subsection{Optimal monetary policy under symmetric coopera- tion}

If all Periphery countries coordinate and act symmetrically, they effectively behave as if they where a single currency area vis-à-vis the Center, that is, they internalize all the cross country effects on employment and inflation of their national monetary policies. Consider first the optimal monetary policy conditional

\footnotetext{
${ }^{20}$ However, if the cooperative agreement can only be reached ex-post, that is, after the realization of $\epsilon_{t}$ has been observed, then the participation constraint is tighter, in that, for each realization of $\epsilon_{t}$, the realized loss under cooperation should be no greater than the realized loss if all countries play Nash.

${ }^{21}$ Likewise, for any size shock, there is always a size of the externality large enough to ensure that all Periphery nations will devalue in an unconstrained cooperative agreement.
} 
on a coordinated symmetric abandonment of the peg. Given that the common objective function is the equally weighted sum of domestic objective functions, the optimal money supply in the representative Periphery country $i$ satisfies

$$
n_{i, t}^{C S}-\bar{n}+\sigma[\alpha+\beta \phi]\left(q_{i, t}^{C S}-\bar{q}\right)=0
$$

where the superscript, $C S$ refers to coordinated symmetric behavior by the Periphery countries. The optimal money supply implies the following shadow depreciation rate, that is now identical in all Periphery countries

$$
\begin{gathered}
\Delta \tilde{s}_{i, t}^{C S}=\frac{1}{A^{C S}}\left[\bar{n}+\left(A^{C S}-\beta \Lambda^{C S}\right) \epsilon_{t}+A^{C S}\left(w_{i, t}-\bar{s}_{i, t}-w_{t}^{*}\right)\right]- \\
-\frac{1}{A^{C S}}\left\{\left[A^{C S}(\alpha+\phi)-\beta \phi \Lambda^{C S}\right] n_{t}^{*}-\Lambda^{C S}\left(\bar{q}_{i, t}-w_{i, t}\right)\right\}
\end{gathered}
$$

where

$$
A^{C S} \equiv \frac{1+\sigma(\alpha+\beta \phi)}{\alpha+\phi} \quad \Lambda^{C S} \equiv \sigma(\alpha+\beta \phi)
$$

By analogy with our analysis of the Nash equilibrium, policy makers will resort, to a coordinated symmetric revaluation or devaluation of the domestic currencies if and only if

$$
\sum_{i=1}^{N} \frac{1}{2}\left\{\left[\left(n_{i, t}^{F X}-\bar{n}\right)^{2}+\sigma\left(q_{i, t}^{F X}-\bar{q}_{i, t}\right)^{2}\right]-\left[\left(n_{i, t}^{F L}-\bar{n}\right)^{2}+\sigma\left(q_{i, t}^{F L}-\vec{q}_{i, t}\right)^{2}\right]\right\} \geq N \mathrm{c}
$$

Following the steps outlined in the previous sections, this policy rule can be written in terms of the SDR

$$
\left|\Delta \tilde{s}_{i t}^{C S}\right| \geq \sqrt{\frac{2 c(\alpha+\phi)}{A^{C S}}} \equiv \tilde{c}^{C S}
$$

As in the case where individual countries play Nash, the optimal choice of exchange rate regime requires the comparison of the SDR with the cost of abandoning the peg expressed in the appropriate metric.

\subsection{The cooperative equilibrium}

The optimal monetary policy in the case of coordinated symmetric behavior of the $N$ countries in the Periphery implies the following reaction functions: if $\left|\Delta \tilde{s}_{i, t}^{C S}\right| \leq \tilde{\mathrm{c}}^{C S}$,

$$
n_{i, t}=\frac{1}{(\alpha+\phi)}\left[\bar{s}_{i, t}-w_{i t}+w_{t}^{*}+(\alpha+\phi) n_{t}^{*}-\epsilon_{t}\right]
$$


while if $\left|\Delta \tilde{s}_{i, t}^{C S}\right| \geq \tilde{c}^{C S}$,

$$
n_{i, t}=\frac{1}{(\alpha+\phi)}\left[\bar{s}_{i, t}+\Delta \tilde{s}_{i, t}^{C S}-w_{i t}+w_{t}^{*}+(\alpha+\phi) n_{t}^{*}-\epsilon_{t}\right]
$$

As the Center country always plays Nash vis-à-vis the Periphery, its reaction function is the same as that given in equation (51).

Solving for the equilibrium yields the following condition: the Periphery will resort to a coordinated symmetric devaluation if and only if

$$
\epsilon_{t} \geq \bar{\epsilon}^{C S} \equiv \frac{1}{\bar{c}^{C S} \Psi_{1}}\left[-\vec{n}+\Psi_{2}\left(\bar{s}_{i, t}-w_{i, t}\right)+\Psi_{3} \tilde{c}^{C S}+\Psi_{4} w_{t}^{*}+\Lambda^{C S}\left(w_{i, t}-\bar{q}_{i, t}\right)\right]
$$

where the parameters $\Psi_{k}$ are defined in Table 2:

$$
\begin{array}{|l|}
\hline \text { TABLE 2 } \\
\Psi_{1}=\left(A^{C S}-\beta \Lambda^{C S}\right)-\alpha \beta H \omega_{3} \\
\Psi_{2}=\Psi_{1}+\beta \Lambda^{C S}+\beta H(\alpha+\phi) \omega_{3} \\
\Psi_{3}=\Psi_{2}-A^{C S} \\
\Psi_{4}=\Psi_{2}-H(\alpha+\phi) \omega_{3} \\
\text { where } \\
\omega_{3}=\frac{A^{C S}(\alpha+\phi)-\beta \Lambda^{C S} \phi}{(\alpha+\phi)(1-H \beta \phi)}=\frac{1+\alpha \Lambda^{C S}}{1-H \beta \phi}
\end{array}
$$

By the same token, a coordinated revaluation of the Periphery currencies vis- $\dot{a}$-vis the center will be implemented for realizations of the shock smaller than $-\bar{\epsilon}^{C S}$. Thus, in a coordinated symmetric equilibrium, Periphery countries will jointly revalue for $\epsilon \leq-\bar{\epsilon}^{C S}$, jointly devalue for $\epsilon \geq \bar{\epsilon}^{C S}$, and jointly maintain the peg for $-\bar{\epsilon}^{C S} \leq \epsilon \leq \bar{\epsilon}^{C S}$.

\section{Does cooperation in the Periphery make a dif- ference?}

This Section is devoted to a comparison of the two equilibrium allocations discussed in the previous sections. The comparison is carried out under the maintained assumption that nominal wages (i.e. private sector's predetermined expectations) are the same across equilibria ${ }^{22}$, so that all Periphery countries are ex-ante identical.

\footnotetext{
${ }^{22}$ This assumption does not violate the analytical consistency of the model, insofar wage setters are ex-ante uncertain about which game national authorities will play after the realization of the shock.
} 
Whether symmetric cooperation is the "best choice" for the Periphery is not immediately evident. On the one hand, common policy actions by the Periphery internalize all the indirect effects of each individual country's monetary policy on other countries' welfare. By definition, these external effects are not taken into consideration by the policy maker in a Nash equilibrium. On the other hand, the maximization of the Periphery joint objective function is constrained. Because of the requirement of (ex-ante and ex-post) symmetry, devaluations or revaluations are implemented only when the shock is sufficiently large (in absolute value) to justify the payment by each country of the sunk cost of a coordinated abandonment of the peg. Thus, the gains from cooperation, stemming from the internalization of intra-Periphery spillovers, are partly offset by the lack of flexibility of an agreement subject to a "symmetry" constraint. In other words, it could be the case that the Periphery countries don't abandon the peg for "relatively small" shocks in a (constrained) symmetric equilibrium. This outcome could be socially inefficient (in terms of the sum of the Periphery countries' loss functions) compared to the (unconstrained) Nash equilibrium in which a subset of the Periphery countries would abandon the peg. It would a-fortiori be socially inefficient compared to the equilibrium under unconstrained cooperation, which would also involve abandonment of the peg by a subset of the Periphery countries. For reasons different from the ones usually pointed out in the literature, (constrained) policy coordination may be counterproductive here.

\subsection{Welfare with positive externalities from monetary ex- pansions in the Periphery.}

Under a freely floating exchange rate with perfect international capital mobility and short-run nominal wage rigidity, we expect that, on balance, monetary expansion in any Periphery country would worsen the international competitiveness of any other Periphery country, that is, $\theta>0{ }^{23}$. We have shown that under the maintained assumption that expenditure-changing effects of a monetary expansion prevail over its expenditure-switching effects in the rest of the Periphery $(\theta>0)$, monetary instruments are strategic complements in the policy game. We now turn to the welfare implications of the international transmission of monetary policies: in the presence of shocks to aggregate demand in the Center, a monetary expansion in country $j$ has a positive external effect on welfare of country $i$.

To see this, consider first the case a shock to aggregate demand in the Center that is high enough to trigger a common devaluation in the Periphery when all countries play Nash. On the one hand, given the money supply (and employment)

\footnotetext{
${ }^{23}$ Note, however, that the total effect of any Periphery country's monetary expansion on welfare in any other Periphery country (and the Center) is positive, because, with given money wages, it lowers the world real interest rate.
} 
in country $i$, higher values of the shock $\epsilon_{t}$ translate, other things equal, into a higher depreciation rate and therefore into a higher level of domestic price (CPI) for country $i$. On the other hand, under our hypotheses about the international transmission of monetary policy, a devaluation by any other Periphery country will induce an appreciation of country $i^{\prime} s$ currency vis-à-vis the Center, partlyoffsetting the inflationary consequences for country $i$ of the shock to aggregate demand in the Center. As the international spillovers of a monetary expansion in country $j$ reduce country $i^{\prime} s$ CPI toward its current target value, the optimal monetary policy (conditional on abandoning the peg) in country $i$ becomes more expansionary, increasing its employment and welfare. By the same token. the deflationary consequences in country $i$ of a negative demand shock in the Center will be dampened when a monetary contraction in country $j$ induces a depreciation of country $i^{\prime} s$ currency vis- $\grave{a}$-vis the Center.

Formally, the response of country $i^{\prime} s$ welfare to a monetary expansion in country $j$ conditional on both countries letting their currencies foat can be calculated by differentiating country $i^{\prime} s$ loss function with respect to country $j^{\prime} s$ employment, and evaluating this expression at the equilibrium level of employment and prices under a float:

$$
\partial \ell_{i}^{F L} / \partial n_{j}=-\sigma\left(q_{i, t}^{F L}-\bar{q}_{i, t}\right) \beta \xi \theta
$$

For sufficiently large values of $\epsilon_{t}$, the Nash equilibrium price level will be above its target level $\bar{q}_{i, t}$ (and Nash equilibrium employment will be below its target level $\bar{n})$. Expression (68) is therefore negative when $\theta$ is positive: a monetary expansion in country $j$ increases welfare in country $i$. The opposite holds in the presence of large negative shocks $\epsilon_{t}$ : as $q_{i, t}^{F L}$ is now below the CPI target, a contraction in country $j$ will be associated with a welfare improvement in country $i$.

In a cooperative equilibrium, the determination of the optimal money supply in the Periphery will take into account the existence of these external effects. So, for any realization of the shock that is large enough to trigger a common devaluation (revaluation), the Periphery as a whole will tend to expand (or contract) more in a symmetric cooperative equilibrium than in a Nash equilibrium. ${ }^{24}$

\footnotetext{
${ }^{24}$ We can also consider the case in which country $j$ expands its money supply but country $i$ maintains a fixed nominal exchange rate vis-a-vis the Center. With the money supply in country $i$ adjusting endogenously to peg the current parity, both employment and the CPI in this country will increase with a monetary expansion by country $j$ provided $\theta>0$. In terms of country $i$ 's loss function, the good news of an increase in the level of activity should therefore be set against the bad news of a higher price level. Over the relevant range of realizations of the shock (that is those values of the shock for which a common devaluation is optimal in a symmetric cooperative equilibrium), the former effect will dominate the latter. This result can easily be established by noting that the square of the SDR is proportional to the difference between the loss under a peg and the loss under a float (net of the sunk cost of realignment). The effect of country $j^{\prime} s$ monetary policy on a country $i$ that pegs its currency can thus be
} 


\subsection{Bilateral and effective exchange rates.}

This Section contrasts the behavior of the exchange rates in the two equilibrium allocations, both at an individual country level and for the Periphery as a whole. For the sake of simplicity and notational thrift, we will only consider realizations of the shock for which the alternatives are a peg and a devaluation against the Center. That is to say, we restrict the support of the shock in such a way that a revaluation by a Periphery country is never optimal, ruling out large negative (present discounted values of the) demand shocks in the Center. The extension to the general case is a simple corollary of the analysis to follow.

In the previous section, we have shown that, within the Periphery, there is a positive welfare externality associated with the international transmission of monetary policy when $\theta$ is positive. Under our assumptions, monetary policy under Nash will be too restrictive compared to a symmetric cooperative policy that fully internalizes such externalities.

The differential behavior of exchange rates is hereafter summarized by Propositions 1 through 4 and illustrated by Figures 2 and 3. For different sets of parameters' values, these Figures plot the share of countries that abandon the peg $\left(N^{F L} / N\right)$, the optimal individual devaluation rates $\left(s_{i, t}-\bar{s}_{i, t}\right)$ and the effective devaluation rate vis-à-vis the Center $\left(\sum_{i}\left(s_{i, t}-\bar{s}_{i, t}\right)\right)$ against the support of the demand shock $\epsilon_{t}$. In all graphs, the solid line refers to the Nash equilibrium, the dashed line to the cooperative allocation. ${ }^{25}$

Consider first the two thresholds $\bar{c}$ and $\tilde{c}^{C S}$. By definition, these variables measure the smallest jump in the exchange rate of any Periphery country that, finds it optimal to abandon the peg (that is, the lower boundary on the size of a bilateral realignment against the Center). Moreover, by construction, they also measure the national welfare cost, of abandoning the peg. It is easy to show ${ }^{26}$

assessed as follows

$$
\frac{\partial \ell_{i}^{F X}}{\partial n_{j}}=\frac{\partial \ell_{i}^{F L}}{\partial n_{j}}+\Delta \tilde{s}_{i, t}\left[\frac{A}{c[\alpha+\xi(1-\alpha)]}\right] \frac{\partial \Delta \tilde{s}_{i, t}}{\partial n_{j}}
$$

As discussed above, the first term in the left-hand-side is negative over the relevant range of the shock. Also, by (47), the SDR of a Periphery country is a negative function of employment in the other Periphery countries. Therefore, the expression (24) is unambiguously negative over the range of the shock associated with $\Delta \tilde{s}_{i, t} \geq 0$. Once again, the case of optimal revaluations only involves a switch in signs: in the presence of a negative realization of the shock, (given quadratic preferences) a monetary expansion by country $j$ reduces welfare in country $i$.

${ }^{25}$ Note that the two allocations (and therefore the two lines) necessarily coincide when there is no external effect of one country's policy actions on other countries' welfare (i.e. $\theta=0$ ).

${ }^{26}$ To prove the inequality in the text, note that the only difference between $\tilde{c}$ and $\tilde{c}^{C S}$ is that the parameter $\phi$ in $\tilde{c}$ is replaced by $\xi(1-\theta)$ in $\tilde{c}^{C S}$. Consider a function $f(x)$ that is obtained from $\tilde{c}$ (or $\tilde{c}^{C S}$ ) by substituting $\phi$ (or $\xi(1-\theta)$ ) with a variable $x$ :

$$
f(x)=\frac{(\alpha+x)^{2}}{1+\sigma(\alpha+\beta x)^{2}}
$$


that the smallest possible optimal devaluation rate is unambiguously higher in a Nash allocation:

$$
\tilde{c} \equiv \sqrt{\frac{2 c[\alpha+\xi(1-\theta)]^{2}}{1+\sigma[\alpha+\beta \xi(1-\theta)]^{2}}} \geq \tilde{c}^{C S} \equiv \sqrt{\frac{2 c(\alpha+\phi)^{2}}{1+\sigma(\alpha+\beta \phi)^{2}}}
$$

This result is apparent in the second graph of Figure 2, when comparing the jumps in the actual devaluation rate for a shock at threshold $\bar{\epsilon}^{d}$ and $\bar{\epsilon}^{C S}$, respectively. The same result is also illustrated in Figure 3, for a different set of parameter values. Accordingly, the minimal welfare cost per country of abandoning the peg is always higher in a Nash than in a coordinated symmetric equilibrium.

We can now turn to our first proposition.

Proposition 1 Coordinated symmetric devaluations occur for smaller realizations of the shock than universal devaluations under Nash:

$$
\bar{\epsilon}^{C S} \leq \bar{\epsilon}^{d}
$$

Consider the threshold value of the shock that, in a Nash equilibrium, triggers a symmetric devaluation by $\tilde{c}$ in all countries $\left(\epsilon_{t}=\bar{\epsilon}^{d}\right)$. As, at the margin, every country is indifferent between pegging or devaluing by $\tilde{c}$, the sum over all Periphery countries of the welfare differential between the two regimes (net of realignment costs) is exactly equal to the total cumulative cost of abandoning the peg, $N c$. By construction, however, for the same level of the shock, the welfare gains from a generalized devaluation by $\tilde{c}$ in the Periphery are higher in the coordinated symmetric equilibrium: the sum of welfare differentials across countries is strictly higher than $N c$ when $\theta>0$. Therefore, using inequality (69) and expressing the welfare differential in the two exchange rate regimes in terms of the shadow depreciation rate, we have

$$
\Delta \tilde{s}^{C S}\left[\bar{\epsilon}^{d}\right] \geq \tilde{c} \geq \tilde{c}^{C S}
$$

As the shadow depreciation rate is increasing in the size of the shock, the threshold value for $\epsilon_{t}$ that trigger a coordinated symmetric devaluation must be lower than $\bar{\epsilon}^{d}$.

For any distribution of the shock, a realignment by all coluntries simultaneously is more likely under symmetric cooperative behavior than under Nash. This result should not be surprising, as it represents an immediate implication of our maintained assumptions about the mechanism of international monetary transmission: as Canzoneri and Henderson put it, "when policy-makers impose positive externalities on one another, cooperation calls for doing more, rather

Observe that $f(x)$ is monotonically increasing in $x$. Since $\phi \equiv \xi(1-N \theta) \leq \xi(1-\theta)$, it follows that $f(\phi) \leq f(\xi(1-\theta))$, verifying the inequality. 
than less". ${ }^{27}$ However, symmetric coordination need not imply more frequent realignments tout-court, as uncoordinated devaluations by a subset of countries are possible also for $\epsilon_{t} \leq \bar{\epsilon}^{d}$. In Figure 3, for instance, when $\epsilon_{t}$ is between $\underline{\epsilon}^{d}$ and $\bar{\epsilon}^{C S}$, some countries will devalue in a Nash equilibrium, while all Periphery countries will maintain the peg under a cooperative agreement. It bears emphasizing that this is not a general result: Figure 2 shows the possibility that, for some configuration of parameters (implying a higher inflationary bias than in Figure 3 ), the trigger point for a generalized devaluation under symmetric cooperation is lower than the threshold at which at least one country realigns under Nash. ${ }^{28}$ In this case, a cooperative agreement delivers less exchange rate stability for any level of the shock in the Center.

The next proposition focuses on the magnitude of realignments rather than on their "timing".

Proposition 2 In general, there exists a range of realizations of the shock for which a Periphery country that abandons the peg devalues more in a Nash equilibrium than in a coordinated symmetric equilibrium. In other words, the subset of countries that devalue in a Nash equilibrium do so at an individual rate higher than the common national devaluation rate in a symmetric coordinated equilibrium.

Consider a realization of the shock such that the periphery is indifferent between a coordinated peg and a coordinated symmetric devaluation, that is $\epsilon_{t}=\bar{\epsilon}^{C S}$. By eq.(69), to the extent that the Nash equilibrium has some countries devaluing, the depreciation rate under Nash is higher than the depreciation rate in a coordinated symmetric equilibrium.

Figure 2 shows that this result is actually quite general, as it may hold also when Periphery countries resort to coordinated devaluations much "before" any country would devalue in a Nash allocation $\left(\underline{\epsilon}_{t}^{d}>\bar{\epsilon}^{C S}\right)$.

Nevertheless, in the aggregate, the following proposition holds:

Proposition 3 For any realization of $\epsilon_{t}$ large enough to trigger a generalized devaluation in the Periphery under symmetric cooperation $\left(\epsilon_{t} \geq \bar{\epsilon}^{C S}\right)$, the effective average devaluation is higher in a coordinated symmetric equilibrium than in a Nash equilibrium:

$$
\frac{1}{N} \sum_{i=1}^{N}\left(s_{i, t}^{C S}-\bar{s}_{i, t}\right) \geq \frac{1}{N} \sum_{i=1}^{N}\left(s_{i, t}-\bar{s}_{i, t}\right), \quad \text { for } \epsilon_{t} \geq \bar{\epsilon}^{C S}
$$

\footnotetext{
${ }^{27}$ Canzoneri-Henderson [1991], p.72.

${ }^{28}$ Policy makers will benefit in this case from "smooth" and frequent realignments (a familiar pattern during the early stages of the ERM).
} 
This Proposition can be verified immediately by taking the average of the Periphery exchange rates vis-à-vis the Center (equation (42)):

$$
\frac{1}{N} \sum_{i=1}^{N} s_{i, t}=(\alpha+\phi)\left(\frac{1}{N} \sum_{i=1}^{N} n_{i, t}-n_{t}^{*}\right)+\left(\frac{1}{N} \sum_{i=1}^{N} w_{i, t}-w_{t}^{*}\right)+\epsilon_{t}
$$

From this expression, it is apparent that the average depreciation is a positive function of the average money stock in the Periphery. A more restrictive average monetary policy under Nash must result in a lower average depreciation rate. A graphical synthesis of these results is given by the plots of the effective devaluation rates in the Periphery at the bottom of Figures 2 and 3.

The nature of the external effect of a Periphery country's monetary policy on the other Periphery countries' welfare provides the rationale for this proposition. For shocks large enough to make all countries devalue in both equilibria, the average money supply in the Periphery will be larger in a symmetric cooperative equilibrium than in a Nash equilibrium. The devaluation rate will correspondingly be higher in the symmetric cooperative equilibrium. For smaller shocks (yet large enough to make all countries devalue in a coordinated symmetric equilibrium), a Nash equilibrium still results in a suboptimally low average monetary expansion in the Periphery, implying an average depreciation lower than in the case of symmetric coordination.

Proposition 3 and 4 together state that, for realization of the shocks to the right of $\bar{\epsilon}^{C S}\left(\epsilon_{t} \geq \bar{\epsilon}^{C S}\right)$, the average devaluation rate is unambiguously higher in a coordinated symmetric allocation, even when the individual country's optimal depreciation rate (conditional on it abandoning the peg) is higher in a Nash equilibrium. Consider now shocks in the left neighborhood of $\bar{\epsilon}^{C S}$, for which no symmetric devaluation is possible, while some Periphery countries would find it optimal to devalue when playing Nash. In such a range of the shock, a Nash equilibrium is characterized by a more expansionary monetary policy than a cooperative one. This possibility is shown in Figure 3. Thus, we can state our last proposition:

Proposition 4 Because of the horizontal equity constraint, there may exist a range of realizations of the shock for which no country devalues in a coordinated symmetric equilibrium, while some countries devalue in a Nash equilibrium. Monetary policy in the system is correspondingly less expansionary in a coordinated equilibrium than in a Nash equilibrium.

The implications of this proposition deserve special attention, as they stress the possibility that, for given wages, ex post welfare could be higher in a Nash equilibrium than in a coordinated symmetric equilibrium. This will be the case for values of $\epsilon_{t}$ that are not large enough to trigger a coordinated symmetric devaluation, but large enough to induce an uncoordinated devaluation by some countries in a Nash equilibrium. For such values of the shock, no cooperation dominates symmetric (and therefore constrained) cooperation. 


\section{Policy coordination and exchange rate crises}

Building on the results of the previous Section, we now turn to the analysis of currency crises in a system of fixed exchange rates, and address the issue of the role played by policy coordination among the Periphery countries. It may be helpful to restate the main features of our theoretical framework. First, individual Periphery countries agree on the desirability (up to a point) of limiting exchange rate flexibility. Formally this is represented by the sunk cost of realignment. The underlying rationale for this may be the recognition by the Periphery countries of their own inflationary bias in the absence of other commitment mechanisms. The exchange rate agreement is seen as a commitment technology, althongh the commitment is less than perfect. The Center provides nominal stability by targeting a time-invariant price level. Policy makers in the Center are inward-looking and the Center always plays Nash vis-à-vis the Periphery. Periphery countries may be willing to coordinate their policies. However, international agreements are enforceable only if they conform to the principle of national horizontal equity, according to which ex-ante identical countries do not agree to cooperate if the outcome of their joint actions implies different levels of national welfare ex-post. Finally, the international transmission of monetary policy in the system is "beggar thy neighbor" through international competitiveness ${ }^{29}$. The source of tension in the system is a large, asymmetric disturbance in the form of a demand shock in the Center, generating pressures for an appreciation of the currency of this country.

In addressing the issue of the impact of such a disturbance on the system, the policy options we focus on are those open to the Periphery countries. Given the conflict of interests between the Center and the Periphery as a whole, due to the fact that each side would benefit from a (costly) monetary expansion in the other side, the starting point of our analysis is that the Center never acts cooperatively. It does not agree to absorb part of the effect of its own aggregate demand shock to the system by letting domestic prices rise above the level that is optimal from its domestic point of view.

An exchange rate arrangement is primarily a mechanism for policy coordination. To the extent that cooperative behavior prevails in the Periphery of the system (and Periphery countries are ex-ante similar to each other), the outcome can be described by using the results in our Section 5 . In response to a demand shock in the Center, the Periphery will tend not to implement a joint (symmetric cooperative) devaluation unless the cost of pegging is high enough to offset the collective welfare cost of reneging on the commitment to peg. Conditional on abandoning the peg, the common devaluation rate will be set in a way that fully internalizes all intra-Periphery international spillovers. Note that under our

\footnotetext{
${ }^{29}$ Expansionary monetary policy in any country (Center or Periphery) also lowers the world real interest rate.
} 
maintained assumptions about the nature of these externalities common (small) realignments are "frequent" as coordinated responses to IS shocks in the Center.

A crisis of the exchange rate system is primarily a crisis of the cooperation agreement that defines and sustains it. In our theoretical framework, there are at least two ways in which a crisis may emerge. First, to the extent that the coordination scheme lacks an effective enforcement mechanism, individual countries always have an incentive to renege on the agreements and play according to their individual reaction functions. Although the hypothesis of an exchange rate crisis stemming from individually deviant behavior raises an issue of logical consistency - why did the deviant countries accept to be part of the system in the first place? $30-$, it, is not unrealistic. Consider a realization of the shock just a bit larger than $\epsilon^{d}$ in Figure 2. While coordination requires a generalized devaluation, national policy makers may be tempted to "save" their currency. After all, as Figure 2 suggests, in a Nash equilibrium just to the right of $\underline{\epsilon}^{d}$, it may take the devaluation of just, one currency to absorb the shock and save the rest of the Periphery from the embarrassment of reneging on the announced exchange rate targets.

Nonetheless, if the Periphery as a whole reverts to undiluted Nash, the (large) devaluation by one country will not be sufficient to modify appreciably the effective terms of trade of the Center. For a shock in that, range, markets (assuming symmetric cooperative behavior) expect a sizable appreciation of the Center real exchange rate, to be achieved through cooperative small uniform individual devaluations of all currencies in the Periphery. Thus, a large devaluation by one country clearly signals to market participants that the exchange rate mechanism as a coordination device has ground to a halt. ${ }^{31}$

A second interpretation of the emergence of a crisis is illustrated in Figure 3. Take a realization of the shock in the range $\left(\underline{\epsilon}^{d}, \bar{\epsilon}^{C S}\right)$. When national horizontal equity is an issue, a Center shock that is large but not large enough to justify a collective devaluation puts the system under considerable stress. If a cooperative defense of the peg prevails, the Center is unhappy, because it cannot benefit from the positive external effects of a more expansionary monetary policy in the periphery. ${ }^{32}$ At the same time, Periphery countries perceive that the individual gains from a unilateral devaluation are high.

The problem of implementing a coordinated but selective (that is, non-universal) devaluation is that there is no way of distributing its costs and benefits evenly

\footnotetext{
${ }^{30}$ This question of course points at political economy considerations, stressing the role of policy makers' changing attitudes towards the international agreement.

${ }^{31}$ It is worthwhile mentioning a possible extension of our framework. When all countries in the Periphery are ex-ante identical, which particular set of countries devalue (or revalue) in a Nash equilibrium is indeterminate. Now introduce a (small) difference between country structures, say, in the determinants of the inflationary bias of country $i\left(\bar{n}_{i} \geq \bar{n}\right)$. Then, extending the logic of our model, we would expect that, in equilibrium, country $i$ would not necessarily be part of the set of devaluing countries, because of its stronger inflationary bias.

${ }^{32}$ The Center being unhappy has no further behavioral implications in our model, as it is assumed to play Nash regardless of whether the periphery coordinates or not.
} 
across nations. ${ }^{33}$ For realizations of the shock under consideration (in the range $\left.\left(\epsilon^{d}, \bar{\epsilon}^{C S}\right)\right)$, the loss in welfare from constrained cooperative behavior is partly avoided in a Nash equilibrium. A Nash equilibrium would accomplish what symmetric coordination cannot: some subset of countries would devalue, making the monetary stance in the system more expansionary (although not by enough to maximize the sum of national welfare functions). If policy makers realize that the system is in such a state, it could be collectively rational to revert to Nash, and thus to implement uncoordinated devaluations. Even if, in the eye of an observer, these devaluations may look like a disorderly response by domestic policy makers to market pressures, they would nonetheless be consistent with (constrained) welfare maximization both at the level of the individual Periphery country and from the point of view of the Periphery as a collective.

What is the role of markets in a crisis of an exchange rate system? The answer to this question is complex, because markets play both an active and a passive role. As regards their active role, in our theoretical framework private sector expectations are reflected in the level of the predetermined nominal variables. Higher nominal wages, ceteris paribus, reduce the stability (and viability) of a peg: all threshold values for the shock determining both coordinated or uncoordinated optimal switches between exchange rate regimes are functions of predetermined nominal variables. Expectations of the future price level are formed by considering the distribution of shocks to an exogenous fundamental 34 , by the market's view on the future conduct of monetary policy, including the rules of the monetary game (Nash or cooperative), and by the way in which the markets and the policy makers coordinate on a particular equilibrium when there are multiple instantaneous equilibria. Multiple instantaneous equilibria (for given fundamentals and rules of the game) should be expected in the class of models under consideration. Given the imperfect credibility of the policy makers' commitment to the peg (implicit in fact that the realignment cost $c$ is finite) it is easily shown that, for a given distribution of the exogenous shocks, there are many possible joint distributions of output, prices and exchange rates when the policy makers cannot, precommit vis-à-vis the private sectors (Obstfeld [1994] and Buiter, Corsetti, and Pesenti [1995]). ${ }^{35}$

\footnotetext{
${ }^{33}$ Note that side payments through fiscal transfers (which we have ruled out in our analysis) have been studied extensively within the theory of optimal currency areas. In such a framework, the stability of the exchange rates is enhanced by taxes and transfers that redice the asymmetric impact of demand shocks. In a similar fashion, a federal fiscal system may also help to solve distributional issues in the design of cooperative policies.

${ }^{34}$ This fundamental is itself a forward-looking variable, reflecting available information on current and future aggregate demand shocks in the Center country.

${ }^{35} \mathrm{~A}$ switch from one instantaneous equilibrium to another (for given fundamentals and rules of the game or assumptions about the nature of the strategic interaction between the players) can be viewed as a speculative attack. Even when the instantaneous equilibrium is unique for given fundamentals and rules of the game (as would be the case with exogenous money wages in our model) the behavior of the system when there is a switch in the strategic behavior of the
} 
On the other hand, once expectations are formed, exchange rate policies are the outcome of rational decision making by domestic authorities that assess costs and benefits of defending the peg, given the current realization of the shock to the fundamental. In this sense, the behavior of the financial markets may be seen as a passive reflection of policy makers' choices, and a currency crisis would be nothing but a financial expression of the tensions that lead to the breaking up of the international agreement on policy coordination.

Can a system of fixed exchange rates survive a crisis that puts into question its viability as a policy coordinating mechanism? In a stationary environment like the one modelled in our paper, the answer to this question depends on two considerations. First, in the light of the crisis, private agents may modify their priors about the likelihood of future cooperative behavior in the policy game. The level of wages and domestic interest rates vary with the market's perception of the nature of the ongoing game among policy makers. Therefore, the post-crisis fixed exchange rate system may be intrinsically more or less fragile, depending on the perceived changes in the nature of the game. Second, as a result of a crisis, policy makers may form coalitions, that is, new agreements among subsets of the players replace the old agreement. For example, a core of a few Periphery countries may either join an enlarged Center (presumably not without the latter's permission) or form a unilateral fixed exchange rate area vis-à-vis the Center (the Core) which systematically excludes the others Periphery countries. Such coalitions might, be more plausible, of course, if there is some ex-ante heterogeneity among the Periphery countries. Through the mechanisms analyzed in the discussion of the Nash allocation, the stability of the bilateral exchange rates in the Core clearly benefits from the free float of the Core vis-à-vis the outsiders' currencies. Of course, the likelihood of future cooperative behavior may not be independent of the size of the coalition, so the two considerations are not independent of each other.

government can be viewed as a a second kind of speculative attack. With an interest-sensitive money demand function (not modelled here), and ad-hoc (and therefore non-strategic) behavior by the anthorities, the anticipation of a higher probability of a crisis will also be associated with a large speculative reshuffle of international portfolios. This represents a third kind of speculative attack; its occurrence will of course depend on the realizations of the fundamentals (typically domestic credit expansion). These three distinct notions of a speculative attack can of course be combined in any number of different ways. 


\section{References}

[1] Alesina A. and V. Grilli [1993], "On the Feasibility of a One or Multi-speed European Union", NBER Working Paper No. 4350

[2] Barro R.J. and D. B. Gordon [1983], "A Positive Theory of Monetary Policy in a Natural Rate Model", Journal of Political Economy, 91, 589-610.

[3] Bulow J., J. Geanakoplos and P. Klemperer [1985], "Multimarket Oligopoly: Strategic Substitutes and Complements", Journal of Political Economy, $93,488-511$

[4] Canzoneri M.B., and D.W. Henderson [1991], Monetary Policy in Interdependent Economy, MIT Press, 1991

[5] De Kock G. and V. Grilli [1993], "Fiscal Policies and the Choice of Exchange Rate Regime", The Economic Journal, 103, 347-358

[6] Drazen A. and Masson P.R. [1994], "Credibility of Policies versus Credibility of Policymakers", Quarterly Journal of Economics, 109, August, pp. 735-54.

[7] Eichengreen, B. and C. Wyplosz [1993], "The unstable E.M.S.", Brookings Papers on Economic Activity, 1, pp. 51-124.

[8] Flood R.P. and Peter M. Garber [1984], "Collapsing Exchange Rate Regimes: Some Linear Examples", Journal of International Economics, 17, 1-13.

[9] Flood R.P. , Jagdeep Bhandari and Jocelyn Horne [1989], "Evolution of exchange rate regimes", IMF Staff Papers, 36, pp. 810-835.

[10] Gerlach, Stefan and Frank Smets [1994], "Contagious speculative attacks", CEPR Discussion Paper No. 1055, November.

[11] Grilli V. [1986], "Buying and Selling Attacks on Fixed Exchange Rate Systems", Journal of International Economics, 20, 143-156

[12] Krugman P. [1979] "A Model of Balance-of-Payments Crises", Journal of Money, Credit and Banking, 11, 311-25

[13] Masson, Paul R. [1995], "Gaining and losing ERM Credibility: the Case of the United Kingdom", Economic Journal, 105, May, pp. 571-582.

[14] Muehring K. [1992], "Currency Chaos: The inside story", Institutional Investor, October, 11-15 
[15] Obstfeld M. [1986], "Rational and Self-fulfilling Balance of Payments Crises", American Economic Review 76, 72-81

[16] Obstfeld M. [1991], "Destabilizing Effects of Exchange Rate Escape clauses", NBER Working Paper 3630

[17] Obstfeld M. [1994], "The Logic of Currency Crises", NBER Working Paper 4640

[18] Obstfeld M. and K. Rogoff [1995], "Sticky-Price Models of Output, the Exchange Rate, and the Current account", in Foundations of International Macroeconomics, ch.9, mimeo.

[19] Ozkan, F. Gulcin and Alan Sutherland [1994a], "Policy Measures to Avoid a Currency Crisis", Mimeo, March, forthcoming in the Economic Journal.

[20] Ozkan F. Gulcin and Alan Sutherland [1994b], "A Currency Crisis Model with an Optimising Policy Maker, University of York, mimeo, June.

[21] Persson T. and G. Tabellini [1995], "Double-edged Incentives: Institutions and Policy Coordination", in G. Grossman and K. Rogoff (eds.), Handbook of International Economics, vol. III, North-Holland, ch. 15, forthcoming. 
Figure 1

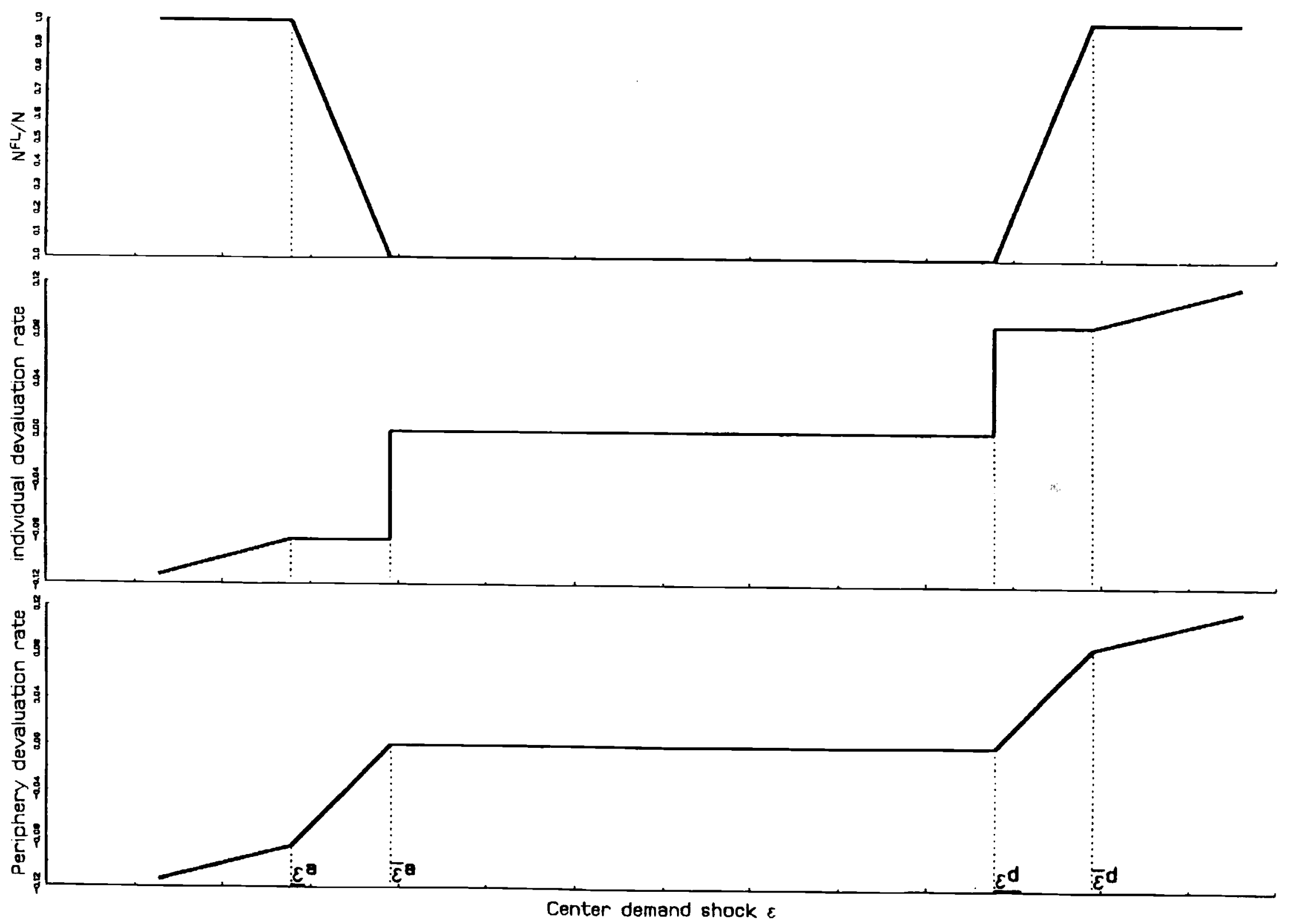


Figure 2
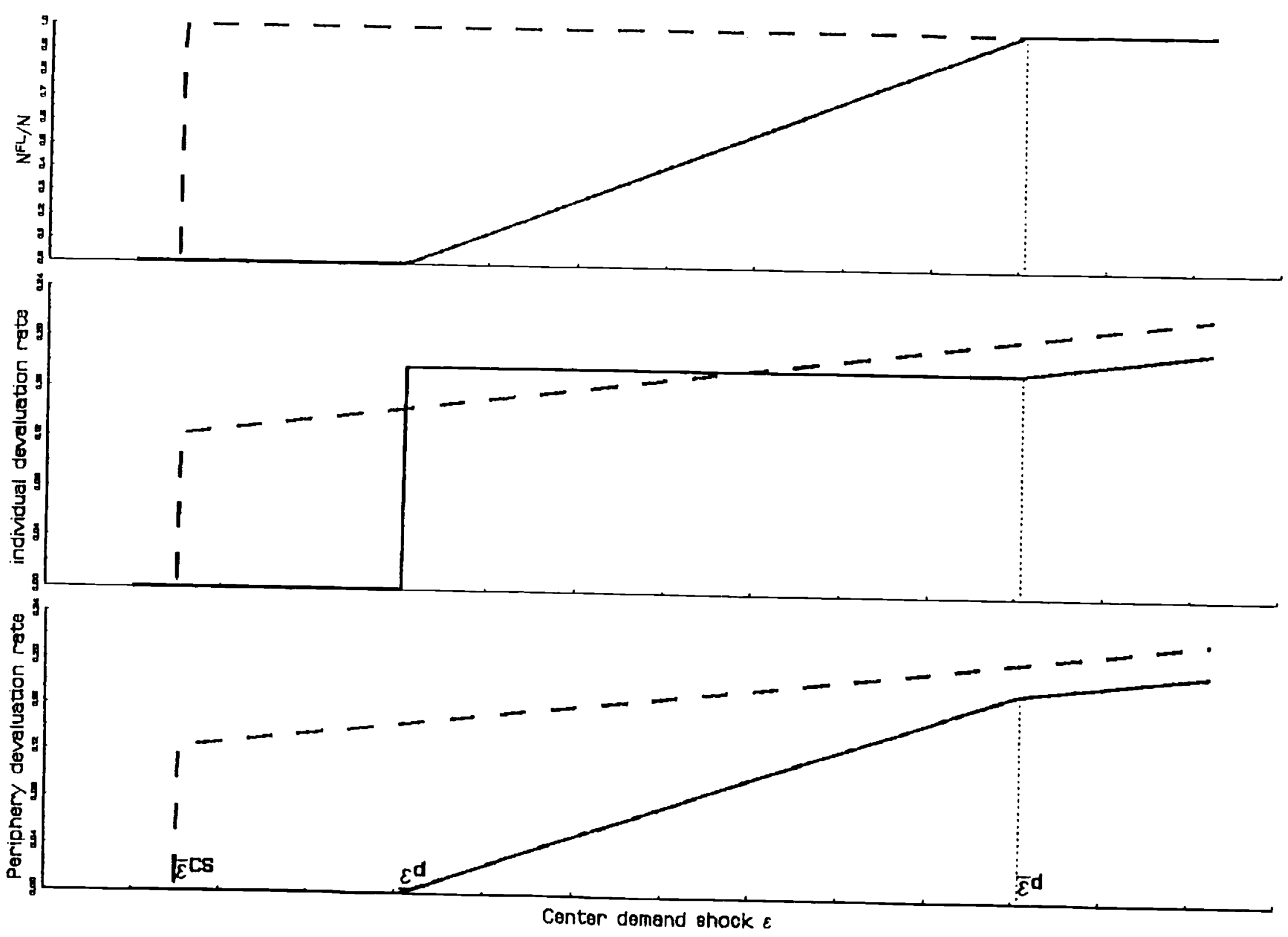
Figure 3

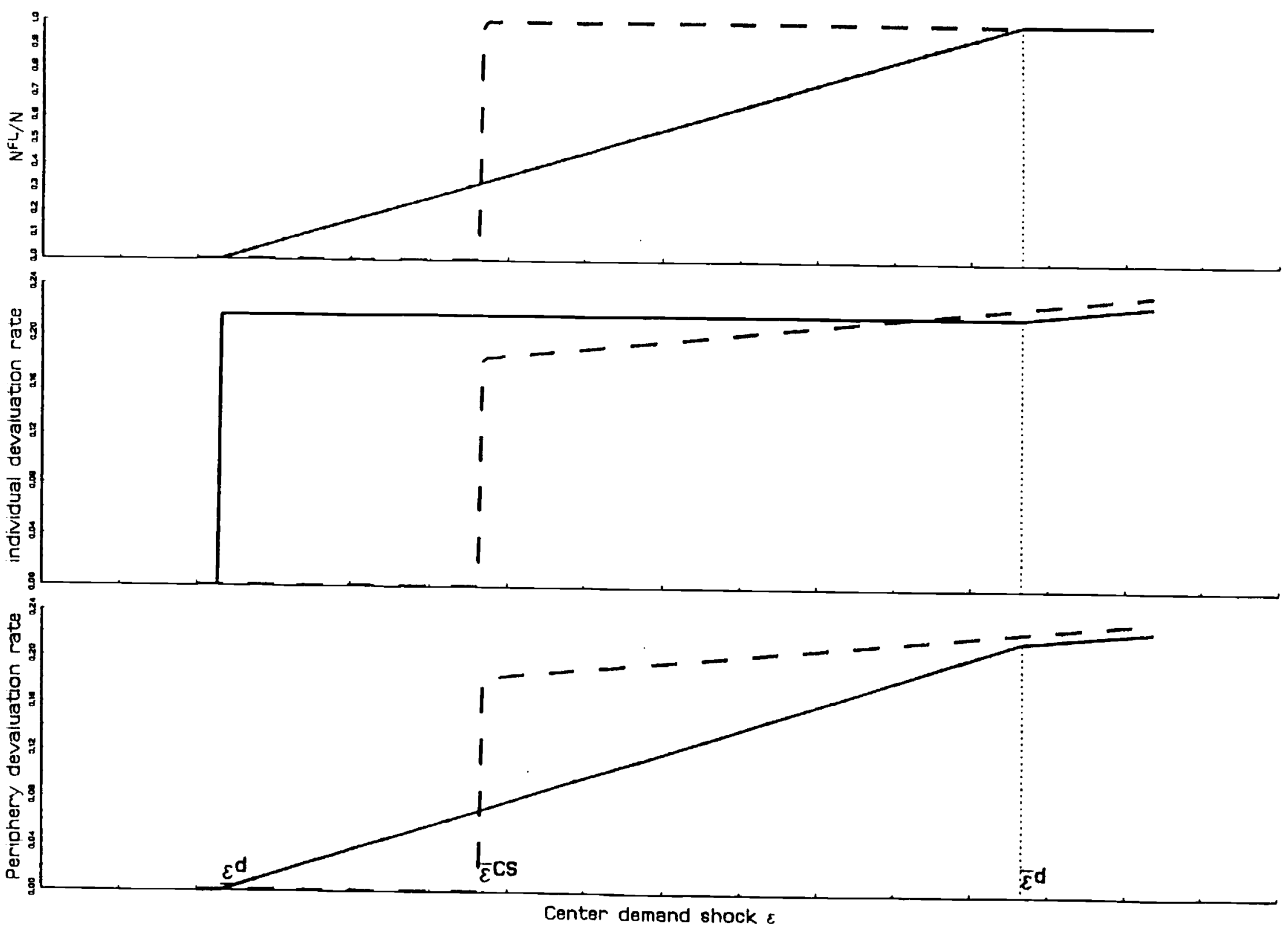

